\title{
\begin{tabular}{l|l} 
Mitraries & DSpace@MIT
\end{tabular}
}

\author{
MIT Open Access Articles
}

\section{Manganese Binding Properties of Human Calprotectin under Conditions of High and Low Calcium: $X-$ ray Crystallographic and Advanced Electron Paramagnetic Resonance Spectroscopic Analysis}

The MIT Faculty has made this article openly available. Please share how this access benefits you. Your story matters.

Citation: Gagnon, Derek M.; Brophy, Megan Brunjes; Bowman, Sarah E. J.; Stich, Troy A.; Drennan, Catherine L.; Britt, R. David and Nolan, Elizabeth M.“Manganese Binding Properties of Human Calprotectin Under Conditions of High and Low Calcium: X-Ray Crystallographic and Advanced Electron Paramagnetic Resonance Spectroscopic Analysis." Journal of the American Chemical Society 137, 8 (March 2015): 3004-3016 (c) 2015 American Chemical Society

As Published: http://dx.doi.org/10.1021/ja512204s

Publisher: American Chemical Society (ACS)

Persistent URL: http://hdl.handle.net/1721.1/110432

Version: Author's final manuscript: final author's manuscript post peer review, without publisher's formatting or copy editing

Terms of Use: Article is made available in accordance with the publisher's policy and may be subject to US copyright law. Please refer to the publisher's site for terms of use. 


\title{
Manganese Binding Properties of Human Calprotectin Under Conditions of High and Low Calcium: X-ray Crystallographic and Advanced EPR Spectroscopic Analysis
}

\author{
Derek M. Gagnon ${ }^{1}$, Megan Brunjes Brophy², Sarah E. J. Bowman ${ }^{2,3}$, Troy A. Stich ${ }^{1}$, \\ Catherine L. Drennan ${ }^{2,3,4}$, R. David Britt ${ }^{1, *}$, and Elizabeth M. Nolan ${ }^{2,{ }^{*}}$ \\ ${ }^{1}$ Department of Chemistry, University of California Davis, Davis, CA 95616, United States \\ 2Department of Chemistry, Cambridge, MA 02139, United States \\ ${ }^{3}$ Howard Hughes Medical Institute, Cambridge, MA 02139, United States \\ ${ }^{4}$ Department of Biology, Massachusetts Institute of Technology, Cambridge, MA 02139, United \\ States
}

\section{Abstract}

The antimicrobial protein calprotectin (CP), a hetero-oligomer of the S100 family members S100A8 and S100A9, is the only identified mammalian Mn(II)-sequestering protein. Human CP uses $\mathrm{Ca}$ (II) ions to tune its $\mathrm{Mn}$ (II) affinity at a biologically unprecedented hexahistidine site that forms at the S100A8/S100A9 interface, and the molecular basis for this phenomenon requires elucidation. Herein, we investigate the remarkable Mn(II) coordination chemistry of human CP using X-ray crystallography as well as continuous wave $(\mathrm{CW})$ and pulse electron paramagnetic resonance (EPR) spectroscopies. An X-ray crystallographic structure of Mn(II)-CP containing one $\mathrm{Mn}(\mathrm{II})$, two $\mathrm{Ca}(\mathrm{II})$, and two $\mathrm{Na}$ (I) ions per $\mathrm{CP}$ heterodimer is reported. The $\mathrm{CW}$ EPR spectrum of $\mathrm{Ca}(\mathrm{II})-$ and $\mathrm{Mn}$ (II)-bound CP prepared with a 10:0.9:1 Ca(II):Mn(II):CP ratio is characterized by an unusually low zero-field splitting of $485 \mathrm{MHz}(E / D=0.30)$ for the $S=5 / 2 \mathrm{Mn}$ (II) ion, consistent with the high symmetry of the $\mathrm{His}_{6}$ binding site observed crystallographically. Results from electron spin-echo envelope modulation and electron nuclear double resonance experiments reveal that the six $\mathrm{Mn}$ (II)-coordinating histidine residues of $\mathrm{Ca}$ (II)- and $\mathrm{Mn}$ (II)-bound $\mathrm{CP}$ are spectroscopically equivalent. The observed ${ }^{15} \mathrm{~N}(I=1 / 2)$ hyperfine couplings $(A)$ arise from two distinct classes of nitrogen atoms: the coordinating $\varepsilon$-nitrogen of the imidazole ring of each histidine ligand $(A=[3.45,3.71,5.91] \mathrm{MHz})$ and the distal $\delta$-nitrogen $(A=[0.11,0.18,0.42]$ $\mathrm{MHz}$ ). In the absence of $\mathrm{Ca}(\mathrm{II})$, the binding affinity of $\mathrm{CP}$ for $\mathrm{Mn}$ (II) drops by ca. two orders of magnitude and coincides with $\mathrm{Mn}$ (II) binding at the $\mathrm{His}_{6}$ site as well as other sites. This study demonstrates the role of $\mathrm{Ca}(\mathrm{II})$ in enabling high-affinity and specific binding of $\mathrm{Mn}$ (II) to the $\mathrm{His}_{6}$ site of human calprotectin.

*Correspondence: Inolan@mit.edu Phone: 617-452-2495 Fax: 617-324-0505 rdbritt@ucdavis.edu Phone: 530-752-6377 Fax: 530-752-8995.

Supporting Information. Tables of protein nomenclature, mass spectrometry, crystal refinement statistics, bond lengths and angles. Figures of overlays of CP structures, additional CW EPR spectra, ENDOR and HYSCORE spectra. This material is available free of charge via the Internet at http://pubs.acs.org.

Conflict of Interest. The authors declare no conflicts of interest. 


\section{Introduction}

Competition between the mammalian host and bacterial pathogens for the essential metal nutrient $\mathrm{Mn}(\mathrm{II})$ is an important facet of the innate immune response and bacterial pathogenesis. ${ }^{1-4}$ Animal models of infectious disease indicate that various human pathogens, including Staphylococcus aureus and Streptococcus pneumoniae, must acquire $\mathrm{Mn}(\mathrm{II})$ in order to establish an infective lifestyle. 1,5,6 The mammalian innate immune system employs the $\mathrm{Ca}(\mathrm{II})-, \mathrm{Mn}(\mathrm{II})-$, and $\mathrm{Zn}$ (II)-binding protein calprotectin (CP) in a metalwithholding strategy that limits $\mathrm{Mn}$ (II) and $\mathrm{Zn}$ (II) availability at sites of infection. ${ }^{7,8} \mathrm{CP}$ is expressed and released by neutrophils and epithelial cells, and exhibits broad-spectrum antimicrobial activity attributed to its metal-binding properties. ${ }^{7-13}$ Moreover, $\mathrm{CP}$ is currently the only host-defense protein identified that sequesters labile Mn(II). Human CP accomplishes this feat by using a biologically unprecedented hexahistidine coordination motif. ${ }^{10,11,13}$

$\mathrm{CP}$ employs $\mathrm{Ca}(\mathrm{II})$ ions to modulate its affinities for $\mathrm{Mn}(\mathrm{II})$ and $\mathrm{Zn}(\mathrm{II}) .{ }^{9,10} \mathrm{In}$ our working model, $\mathrm{CP}$ turns on its metal-sequestering ability in the $\mathrm{Ca}$ (II)-rich (i.e. low-millimolar concentrations) extracellular space such that it can outcompete invading pathogens for these transition metal ions. Nevertheless, the molecular basis for how $\mathrm{Ca}$ (II) ions enable $\mathrm{CP}$ to transition from a relatively low- to a relatively high-affinity form, as well as how the unusual hexahistidine site allows $\mathrm{CP}$ to entrap labile $\mathrm{Mn}$ (II), requires elucidation. In the present work, we employ X-ray crystallography and electron paramagnetic resonance (EPR) spectroscopy to interrogate the mechanism by which $\mathrm{Ca}(\mathrm{II})$ ions modulate complexation of $\mathrm{Mn}(\mathrm{II})$ by CP.

$\mathrm{CP}$ is a member of the $\mathrm{Ca}(\mathrm{II})$-binding $\mathrm{S} 100$ protein family. S100 proteins employ helixloop-helix EF-hand domains for $\mathrm{Ca}$ (II) coordination, and several members of this family (e.g. S100A7, S100A12, S100B, CP) exhibit additional binding sites for transition metal ions. ${ }^{14,15} \mathrm{CP}$ forms heterodimers and tetramers of S100A8 (93 amino acids, $10.8 \mathrm{kDa}, \mathrm{\alpha}$ ) and S100A9 (114 amino acids, $13.2 \mathrm{kDa}, \beta$ ). ${ }^{16-18}$ Whether CP exists as the $\alpha \beta$ or $\alpha_{2} \beta_{2}$ oligomer depends on $\mathrm{Ca}(\mathrm{II})$. In the absence of $\mathrm{Ca}(\mathrm{II})$, the $\alpha \beta$ heterodimer predominates whereas $\mathrm{Ca}(\mathrm{II})$ binding results in formation of the $\mathrm{a}_{2} \beta_{2}$ tetramer. ${ }^{17-19}$

The Ca(II)-binding sites of CP have been structurally characterized. ${ }^{18}$ Each S100 subunit exhibits two EF-hand domains (Table 1), and each subunit has been proposed to coordinate two $\mathrm{Ca}$ (II) ions such that the $\mathrm{CP}$ heterodimer contains four distinct $\mathrm{Ca}$ (II)-binding sites. ${ }^{18}$ The C-terminal EF-hand of each subunit resembles the $\mathrm{Ca}(\mathrm{II})$-binding domains of calmodulin and is therefore described as canonical. ${ }^{20,21}$ The N-terminal EF-hands exhibit lower coordination numbers and are often termed non-canonical. ${ }^{20,22,23} \mathrm{The} \mathrm{Ca}(\mathrm{II})$ coordinating groups of S100A8 and S100A9 identified in prior crystallographic structural work, as well as the coordination numbers and net charges of these EF-hands, are summarized in Table 1. The Ca(II)-binding affinities of the CP EF-hands have not been determined; however, $\mathrm{Ca}(\mathrm{II})$ affinities of other $\mathrm{S} 100$ proteins have been reported. ${ }^{20,22,24,25}$ In general, the reported dissociation constant $\left(K_{\mathrm{d}}\right)$ values for $\mathrm{Ca}(\mathrm{II})$ of canonical EF-hands are $1-50 \mu \mathrm{M}$ whereas the $K_{d}$ values for non-canonical EF-hands are $100-500 \mu \mathrm{M}$. The 
relatively weak $\mathrm{Ca}(\mathrm{II})$ affinities of non-canonical EF-hands are consistent with both the lower coordination numbers and the reduced negative charge exhibited by these motifs. Moreover, it has been proposed that the $\mathrm{Ca}$ (II) affinities of the $\mathrm{N}$-terminal non-canonical EF-hands may be too weak to appreciably bind $\mathrm{Ca}$ (II) in a physiological context. ${ }^{22}$

Each CP heterodimer contains two transition-metal-ion binding sites at the dimer interface that are distinct from the $\mathrm{Ca}(\mathrm{II})$-binding sites. ${ }^{9,18}$ Site 1 is a His ${ }_{3} \mathrm{Asp}$ motif comprised of His83 and His87 from S100A8, and His20 and Asp30 from S100A9. Site 2 is an unusually histidine-rich biological metal-binding site and has been described as a $\mathrm{His}_{4} \mathrm{Or} \mathrm{His}_{6}$ motif. ${ }^{10,11,13}$ The His 4 motif, which is observed crystallographically at the S100A8/S100A9 interface in the absence of a bound transition metal ion, ${ }^{18}$ contains His17 and His27 of S100A8 and His91 and His95 of S100A9. The S100A9 subunit has an extended C-terminal tail that is disordered in the absence of a coordinated Mn(II) ion. Structural ${ }^{13}$ and biochemical ${ }^{11}$ studies of $\mathrm{Mn}(\mathrm{II})$-bound $\mathrm{CP}$ revealed that site 2 binds $\mathrm{Mn}(\mathrm{II})$ in an octahedral $\mathrm{His}_{6}$ motif in which His103 and His105 of the S100A9 tail provide the fifth and sixth ligands. Both sites 1 and 2 can coordinate $\mathrm{Mn}(\mathrm{II})$, and we previously identified site 2 as the high-affinity $\mathrm{Mn}$ (II)-binding site. ${ }^{10}$ Moreover, we proposed that encapsulation of $\mathrm{Mn}$ (II) by the tail region allows $\mathrm{CP}$ to bind and restrict dissociation of this labile metal ion. ${ }^{11}$

In this work, we probe the molecular basis for Mn(II) sequestration by CP using X-ray crystallography and EPR spectroscopy. We present a new crystallographic snapshot of $\mathrm{Mn}(\mathrm{II})-\mathrm{CP}$ that reveals a 1:1 $\mathrm{Mn}(\mathrm{II}): \mathrm{CP}(\alpha \beta)$ stoichiometry with $\mathrm{Mn}$ (II) exclusively bound to the $\mathrm{His}_{6}$ site and $\mathrm{Ca}$ (II) bound to each of the two canonical C-terminal EF-hands of the $\alpha \beta$ heterodimer. We conclude that the non-canonical EF-hands located in the N-terminal regions of S100A8 and S100A9 coordinate $\mathrm{Na}(\mathrm{I})$ under the crystallographic conditions used in this work. Moreover, we establish that the $\mathrm{Mn}(\mathrm{II})-\mathrm{His}_{6}$ site of $\mathrm{Ca}(\mathrm{II})$-bound $\mathrm{CP}$ is highly symmetric in solution, and that the C-terminal tail region of S100A9 is essential for preventing water access to the $\mathrm{Mn}$ (II) center. We demonstrate, for the first time, that $\mathrm{Mn}$ (II) binding in the absence of $\mathrm{Ca}$ (II) results in $\mathrm{Mn}$ (II) coordination to the $\mathrm{His}_{6}$ site as well as additional sites. These findings indicate that $\mathrm{Ca}$ (II) binding leads to specific and highaffinity $\mathrm{Mn}(\mathrm{II})$ coordination to the $\mathrm{His}_{6}$ site. In total, our work illuminates the molecular basis for $\mathrm{Mn}(\mathrm{II})$ capture by $\mathrm{CP}$ in the presence of $\mathrm{Ca}(\mathrm{II})$, and supports a model in which $\mathrm{Ca}$ (II) binding promotes $\mathrm{Mn}$ (II) sequestration in an octahedral $\mathrm{Mn}$ (II)-His ${ }_{6}$ coordination environment that precludes water molecules from the primary coordination sphere.

\section{Experimental Section}

\section{General Materials and Methods}

All solvents, reagents, and chemicals were obtained from commercial suppliers and used as received. All buffers and metal stock solutions were prepared using Milli-Q water (18.2 M $\Omega$, $0.22-\mu \mathrm{m}$ filter). All buffers employed for spectroscopy samples were prepared in acidwashed volumetric glassware using Ultrol grade HEPES (free acid, Calbiochem) and TraceSELECT NaCl (Sigma). PEG 200 was purchased from Hampton Research. Calcium chloride was purchased from Sigma Aldrich, and 99.999\% manganese chloride was purchased from Alfa Aesar. Stock solutions of 1.0 M Ca(II) or Mn(II) were prepared in Milli-Q water using acid-washed volumetric glassware and immediately transferred to 
polypropylene tubes for long-term storage. Working metal solutions were prepared fresh daily by diluting the appropriate stock solution with buffer $(75 \mathrm{mM}$ HEPES, $100 \mathrm{mM} \mathrm{NaCl}$, pH 7.5). ${ }^{15} \mathrm{~N}$-Ammonium chloride $\left({ }^{15} \mathrm{NH}_{4} \mathrm{Cl}, 99 \%\right)$ and deuterium oxide $\left({ }^{2} \mathrm{H}_{2} \mathrm{O}, 99.9 \%\right)$ were obtained from Cambridge Isotope Laboratories, INC (Andover, MA). Table S1 (Supporting Information) lists the proteins used in this work and corresponding nomenclature. Unlabeled CP-Ser, $\Delta$ His $_{3}$ Asp, H103A, H104A, H105A, H103A/H105A (AHA), and H103A/H104A/H105A (AAA) were overexpressed and purified as described previously. ${ }^{9} \mathrm{CP}-\mathrm{Ser}$ and mutants thereof were employed in this work because mutation of Cys42 of S100A8 and Cys3 of S100A9 to Ser residues allows metal-binding studies to be performed in the absence of a reducing agent. ${ }^{9}$ All protein concentrations are reported in terms of the $\alpha \beta$ heterodimer. Equivalents of divalent cations are reported in terms of the $\alpha \beta$ heterodimer.

\section{Preparation of ${ }^{15} \mathrm{~N}$-labeled CP-Ser and Mutants}

Globally ${ }^{15}$ N-labeled S100A8(C42S), S100A8(C42S)(H83A)(H87A), S100A9(C3S), and S100A9(C3S)(H20A)(D30A) were obtained by overexpression in M9 minimal medium containing $6 \mathrm{~g} / \mathrm{L}$ anhydrous $\mathrm{Na}_{2} \mathrm{HPO}_{4}, 3 \mathrm{~g} / \mathrm{L}$ anhydrous $\mathrm{KH}_{2} \mathrm{PO}_{4}, 0.5 \mathrm{~g} / \mathrm{L} \mathrm{NaCl}, 2 \mathrm{mM}$ $\mathrm{MgSO}_{4}, 100 \mu \mathrm{M} \mathrm{CaCl}_{2}, 1 \mathrm{~g} / \mathrm{L}^{15} \mathrm{NH}_{4} \mathrm{Cl}$, and $2 \mathrm{~g} / \mathrm{L}{ }_{\text {D-glucose. The medium was aseptically }}$ filtered, and a 1-L volume was transferred to an autoclaved 4-L baffled flask. The minimal medium (1 L) was supplemented with a $400-\mu \mathrm{L}$ aliquot of a vitamin mix (400 $\mathrm{mg}$ choline chloride, $500 \mathrm{mg}$ folic acid, $1.1 \mathrm{~g}$ pantothenic acid, $500 \mathrm{mg}$ nicotinamide, $500 \mathrm{mg}$ myoinositol, $500 \mathrm{mg}$ pyridoxal $\mathrm{HCl}, 500 \mathrm{mg}$ thiamine $\mathrm{HCl}$, and $50 \mathrm{mg}$ riboflavin suspended in $15 \mathrm{~mL}$ of Milli-Q water) and a spatula tip of iron(III) chloride hexahydrate immediately prior to use.

The plasmids pET41a-S100A9(C3S), pET41a-S100A8(C42S), pET41a-S100A9 (C3S)(H2OA) (D30A), and pET41a-S100A8(C42S)(H83A)(H87A) were transformed into chemicallycompetent $E$. coli BL21(DE3) cells. ${ }^{9}$ Single colonies were selected and utilized to inoculate $50 \mathrm{~mL}$ of Luria Broth (LB) medium containing kanamycin $(50 \mu \mathrm{g} / \mathrm{mL})$. Cultures were incubated overnight (ca. $16 \mathrm{~h}$ ) at $37^{\circ} \mathrm{C}$ with shaking at $175 \mathrm{rpm}$ in $250-\mathrm{mL}$ baffled flasks. The cultures were transferred to sterile $50-\mathrm{mL}$ conical tubes and pelleted by centrifugation (3000 rpm $\times 30 \mathrm{~min}, 4{ }^{\circ} \mathrm{C}$ ). The supernatant was decanted, and each cell pellet was washed by resuspending the cells with ca. $25 \mathrm{~mL}$ of minimal medium (vide supra) and pelleting by centrifugation $\left(3000 \mathrm{rpm} \times 30 \mathrm{~min}, 4^{\circ} \mathrm{C}\right)$. The resulting cell pellet was resuspended in ca. $25 \mathrm{~mL}$ of minimal medium and the entire volume was used to inoculate $1 \mathrm{~L}$ of minimal medium prepared as described above. The cultures were incubated at $37{ }^{\circ} \mathrm{C}$ with shaking at $175 \mathrm{rpm}$ and protein overexpression was induced by addition of $500 \mu \mathrm{M}$ of IPTG when the $\mathrm{OD}_{600}$ reached ca. 0.6. The cultures were incubated for an additional $3.5 \mathrm{~h}$ at $37^{\circ} \mathrm{C}\left(\mathrm{OD}_{600}\right.$ $\sim 1.2$ ) at which time the cells were harvested by centrifugation (3000 rpm $\times 15 \mathrm{~min}, 4^{\circ} \mathrm{C}$ ). The cell pellets were transferred to sterile $50-\mathrm{mL}$ conical tubes, flash frozen in liquid nitrogen, and stored at $-80^{\circ} \mathrm{C}$ for up to six weeks. The resulting yields ranged from approximately $1.0-2.0 \mathrm{~g}$ cells / $\mathrm{L}$ of culture.

Globally ${ }^{15} \mathrm{~N}$-labeled CP-Ser and $\Delta \mathrm{His}_{3}$ Asp were purified and stored as described previously, ${ }^{9}$ and the yields ranged from 3-7 mg of ${ }^{15} \mathrm{~N}$-labeled protein $/ 2 \mathrm{~L}$ of culture. For 
mixed-labeled proteins where only S100A8 or S100A9 was ${ }^{15} \mathrm{~N}$-labeled, the unlabeled subunit was overexpressed in $\mathrm{M} 9$ minimal medium containing $\mathrm{NH}_{4} \mathrm{Cl}$ with natural abundance. For all protein purifications, the final size-exclusion chromatography and dialysis steps were performed at $\mathrm{pH} 8.0(20 \mathrm{mM}$ HEPES, $100 \mathrm{mM} \mathrm{NaCl})$ as described previously, ${ }^{9}$ and the purified proteins were stored at $-80{ }^{\circ} \mathrm{C}$ until further use. Protein purity and identity were confirmed by SDS-PAGE (Figure S1) and LC/MS (Table S2).

\section{Crystallization of Mn(II)-CP-Ser}

$\mathrm{Mn}(\mathrm{II})-\mathrm{CP}-\mathrm{Ser}$ was crystallized at $18{ }^{\circ} \mathrm{C}$ employing the sitting drop vapor diffusion technique. Screening of crystallization conditions using an automated Phoenix crystallization robot (Art Robbins Instrument) and Crystal Screen HT (Hampton Research) yielded a crystal that appeared between days 3 and 5 . The droplets contained $100 \mathrm{~nL}$ of protein solution, $100 \mu \mathrm{M} \mathrm{CP}$-Ser, $100 \mu \mathrm{M} \mathrm{MnCl}_{2}, 1.0 \mathrm{mM} \mathrm{CaCl}_{2}$, at $\mathrm{pH} 7.5(75 \mathrm{mM}$ HEPES, $100 \mathrm{mM} \mathrm{NaCl}$ ) and $100 \mathrm{~nL}$ of precipitant solution, 20\% (w/v) PEG 4000, 20\% (v/v) isopropanol, $0.1 \mathrm{M}$ sodium citrate at $\mathrm{pH} 5.6$, and were equilibrated against $100 \mu \mathrm{L}$ of precipitant solution in a 96-well Intelliplate (Art Robbins Instruments). The crystal was transferred to a cryogenic solution (20\% PEG 4000, 10\% glycerol) and flash-frozen in liquid nitrogen.

\section{Data Collection and Structure Determination}

Diffraction data were collected at the 24-ID-C beamline at the Advanced Photon Source (APS) at Argonne National Laboratory using a Pilatus 6M pixel detector. APS datasets were collected at a wavelength of $0.9792 \AA(12662.0 \mathrm{eV})$ in $0.3^{\circ}$ oscillation steps. Additional diffraction data was collected on the same crystal at $100 \mathrm{~K}$ using an in-house $\mathrm{Cu}-\mathrm{K}_{\mathrm{a}}$ rotating anode source (Rigaku) at a wavelength of $1.5418 \AA$ with a Saturn 944 CCD detector, using sequential $1^{\circ}$ oscillation steps. The structure was completed with SBGrid compiled software. ${ }^{26}$ Data were integrated and scaled in space group $P 2(a=55.2 \AA, b=49.2 \AA, c=$ 218.1 $\AA$, $\alpha=\gamma=90$ and $\beta=94.1)$, using HKL2000 software. ${ }^{27}$ Two and a half tetramers are contained within the asymmetric unit. The structure was determined at $2.5 \AA$ resolution by molecular replacement using protein atoms from chains A and C of PDB entry 4GGF in PHASER. ${ }^{13,28}$ Iterative rounds of refinement in PHENIX without use of noncrystallographic symmetry restrains or a sigma cutoff, and model building in COOT achieved a final model at $1.76 \AA$ resolution. ${ }^{29,30}$ Initial difference electron density maps revealed density consistent with the presence of five $\mathrm{Mn}$ (II) in the five $\mathrm{His}_{6}$ sites, $10 \mathrm{Ca}$ (II) ions in the 10 canonical C-terminal EF-hand sites, and 10 ions in the 10 non-canonical Nterminal EF-hand sites of the asymmetric unit. To further probe the identity of the metals in the metal-binding sites, in-house diffraction data, processed using HKL2000, was employed to generate anomalous density maps. The anomalous data are consistent with five $\mathrm{Mn}$ (II) and $10 \mathrm{Ca}(\mathrm{II})$ ions in the asymmetric unit. There is no anomalous density observed at the non-canonical EF-hand sites. To best fit the electron density in these sites, and yield $B$ factors similar to the rest of the protein, $\mathrm{Na}(\mathrm{I})$ is modeled into both the S100A8 and S100A9 non-canonical N-terminal EF-hand sites at $100 \%$ occupancy. The crystallization conditions contained $100 \mathrm{mM} \mathrm{NaCl}$ in the protein solution (100-fold excess relative to CP-Ser). Metal ions and water molecules were added to the model at 2.0- $\AA$ resolution. The model contains 8921 total atoms; chains $\mathrm{C}$ and $\mathrm{E}$ contain residues 1-89 (of 93, S100A8), chains A, G, and I 
contain residues 1-88 (of 93, S100A8), chains B, F, and J contain residues 4-111 (of 114, S100A9), and chains D and H contain residues 4-112 (of 114, S100A9). Composite omit maps were used to verify the structure. The crystallographic data refinement and statistics are provided in Table S3.

\section{Preparation of EPR Samples}

Aliquots of CP-Ser or mutated forms of CP-Ser were thawed on ice and buffer exchanged into $75 \mathrm{mM}$ HEPES, $100 \mathrm{mM} \mathrm{NaCl}, \mathrm{pH}$ 7.5. The protein concentration was determined by absorbance at $280 \mathrm{~nm}\left(\varepsilon=18,450 \mathrm{M}^{-1} \mathrm{~cm}^{-1}\right.$ for CP-Ser $(\mathrm{a} \beta)$ and mutants presented herein). For $+\mathrm{Ca}$ (II) EPR samples, a solution $(150 \mu \mathrm{L})$ of $200 \mu \mathrm{M} \mathrm{CP}$ at pH $7.5(80 \%(\mathrm{v} / \mathrm{v}) 75 \mathrm{mM}$ HEPES, $100 \mathrm{mM} \mathrm{NaCl}, 20 \%$ (v/v) PEG 200) was prepared in a microcentrifuge tube, and $\mathrm{Ca}(\mathrm{II})$ was added from a 100-mM stock solution to afford a final concentration of $2 \mathrm{mM}$. The resulting mixture was incubated at room temperature for ca. $20 \mathrm{~min}$. For $+\mathrm{Ca}$ (II) samples, $\mathrm{Mn}$ (II) was then added from a 10-mM stock solution to afford a final concentration of $180 \mu \mathrm{M}(0.9$ equiv. / $\mathrm{CP} \alpha \beta)$, and the sample was incubated at room temperature for 20 min. The sample was then transferred to a quartz (CFQ) EPR tube with an outer diameter of $3.8 \mathrm{~mm}$ (Wilmad, 706-PQ-9.50), frozen in liquid nitrogen, and stored in liquid nitrogen.

For $+\mathrm{Ca}$ (II) samples prepared in ${ }^{2} \mathrm{H}_{2} \mathrm{O}$, protein aliquots were thawed and buffer exchanged as described above, and $\mathrm{CP}$ was diluted to $100 \mu \mathrm{M}(300 \mu \mathrm{L})$ at pH 7.5 (75 mM HEPES, 100 $\mathrm{mM} \mathrm{NaCl})$. An aliquot of aqueous $\mathrm{Ca}(\mathrm{II})(100 \mathrm{mM})$ was added to each sample to afford a final $\mathrm{Ca}$ (II) concentration of $1 \mathrm{mM}$ (10 equiv. / $\alpha \beta$ ), and the resulting sample was incubated at room temperature for ca. $20 \mathrm{~min}$. An aliquot of $\mathrm{Mn}(\mathrm{II})(10 \mathrm{mM})$ was then added to achieve a final concentration of $90 \mu \mathrm{M}(0.9$ equiv. / CP $\alpha \beta)$ and the sample was incubated at room temperature for ca. $20 \mathrm{~min}$. The resulting samples were frozen in liquid nitrogen and lyophilized to dryness. To exchange $\mathrm{H}_{2} \mathrm{O}$ for ${ }^{2} \mathrm{H}_{2} \mathrm{O}$, each sample was re-suspended in 300 $\mu \mathrm{L}$ of ${ }^{2} \mathrm{H}_{2} \mathrm{O}$ and lyophilized to dryness. This process was repeated for a total of three times. Following the third lyophilization, each sample was dissolved in $150 \mu \mathrm{L}$ of ${ }^{2} \mathrm{H}_{2} \mathrm{O}$ containing $20 \%$ (v/v) PEG 200 to afford a sample containing $200 \mu \mathrm{M} \mathrm{CP}, 2 \mathrm{mM} \mathrm{Ca}(\mathrm{II})$, and $180 \mu \mathrm{M}$ $\mathrm{Mn}(\mathrm{II})$. Each sample was transferred to an EPR tube, frozen in liquid nitrogen, and stored in liquid nitrogen. For experiments at Q-band, several samples were thawed and transferred into quartz EPR tubes $(2.4 \times 2.0 \mathrm{~mm})$, and frozen in liquid nitrogen.

The $-\mathrm{Ca}$ (II) samples were prepared as described above except that samples contained 180 $\mu \mathrm{M} \mathrm{Mn}(\mathrm{II})$ and either $1.0 \mathrm{mM}$ or $200 \mu \mathrm{M}$ CP. No Ca(II) was added.

\section{Electron Paramagnetic Resonance Spectroscopy}

EPR spectra were collected at the CalEPR Center at the University of California, Davis. All X-band (ca. 9.4 GHz) continuous wave (CW) EPR spectra were collected under nonsaturating, slow-passage conditions using a Bruker E500 equipped with a super high QE (SHQE) resonator and Oxford Instruments ESR900 cryostat. The time constant was set to 80 $\mathrm{ms}$ with a data point collected ca. every $0.4 \mathrm{mT}$. A Bruker ELEXYS E580 spectrometer with X- and Q- $(\approx 34.1 \mathrm{GHz})$ band capabilities was used to collect all pulse EPR spectra. An Oxford Instruments CF935 continuous-flow liquid-helium cryostat was employed for cryogenic temperatures. A Bruker MS5 or MD4 resonator was utilized to collect X-band 
pulse spectra. A home-built probe based on previously published designs was employed to collect Q-band pulse spectra. ${ }^{31}$ All low-temperature data were collected at $10 \mathrm{~K}$ with the exception of Davies ENDOR, which was performed at $4.5 \mathrm{~K}$. Additional experimental parameters are listed in the corresponding figure captions. Standard 2-pulse ( $\pi / 2-\tau-\pi-\tau$ echo), 3-pulse ( $\pi / 2-\tau-\pi / 2-\mathrm{T}-\pi / 2$ - $\tau$-echo), and 4-pulse ( $\pi / 2-\tau-\pi / 2-\mathrm{T}-\pi$-T- $\pi / 2$ - $\tau$-echo) electron spin-echo envelope modulation (ESEEM) sequences as well as hyperfine sublevel correlation spectroscopy (HYSCORE, $\pi / 2-\tau-\pi / 2-\mathrm{T}_{1}-\pi-\mathrm{T}_{2}-\pi / 2-\tau$-echo) were used to probe the hyperfine coupling between the nitrogen nuclei in close proximity to the $\mathrm{Mn}$ (II) ion. Mims ( $\pi / 2-\tau-\pi / 2-\pi_{\mathrm{RF}^{-}} \pi / 2$ - $\tau$-echo) and Davies ( $\pi-\pi_{\mathrm{RF}^{-}} \pi / 2-\tau$ - $\pi$ - $\tau$-echo) electron-nuclear double resonance (ENDOR) spectroscopies were used to measure the ${ }^{15} \mathrm{~N}$ and ${ }^{1} \mathrm{H}$ hyperfine couplings, respectively. ${ }^{32,33}$ Room temperature X-band EPR (RT-EPR) was performed with $10 \mu \mathrm{L}$ of each sample in a capillary melting point tube (Kimble-Chase) using the Bruker SHQE resonator without the cryostat insert.

\section{EPR Data Analysis}

Time domain spectra were corrected for electron relaxation by subtracting a bi-exponential decay. These time traces were then apodized using a Hamming function and zero-filled (8fold the length of the original time trace) prior to Fourier-transformation using cross-term averaging (ca. 40-60 cycles) to minimize deadtime-induced artifacts. ${ }^{34}$ To determine spin Hamiltonian parameters, simulations were performed using the EasySpin toolbox for MATLAB (The Mathworks Inc.). ${ }^{35}$ The spin Hamiltonian for the ${ }^{55} \mathrm{Mn}$ (II) $(I=5 / 2,100 \%$ natural abundance) spin system is defined by eq. 1 .

$$
\hat{\mathbf{H}}=\beta_{e} \hat{\mathbf{B}} \cdot \boldsymbol{g} \cdot \hat{\boldsymbol{S}} / h+\sum_{\boldsymbol{i}}\left(\hat{\boldsymbol{S}} \cdot \mathbf{A}_{\mathbf{i}} \cdot \hat{\boldsymbol{I}}_{\boldsymbol{i}}+\hat{\boldsymbol{I}}_{\boldsymbol{i}} \cdot \mathbf{P}_{\mathbf{i}} \cdot \hat{\boldsymbol{I}}_{\boldsymbol{i}}-\beta_{n} g_{n, j} \hat{\mathbf{B}} \cdot \hat{\boldsymbol{I}}_{\boldsymbol{i}}\right)+\hat{\boldsymbol{S}} \cdot \mathbf{D} \cdot \hat{\boldsymbol{S}}
$$

The terms, in order, are the electron Zeeman interaction with a static magnetic field $\mathbf{B}$, the electron-nuclear hyperfine (HF) tensor $\mathbf{A}_{\mathbf{i}}$ for every nucleus $i$ with a non-zero nuclear spin (I) that is coupled to the $\mathrm{Mn}(\mathrm{II})$ center, the nuclear quadrupole tensor $\mathbf{P}_{\mathbf{i}}$ for nuclei with $I>$ $1 / 2$, the nuclear Zeeman interaction, and the zero-field splitting (ZFS) tensor $\mathbf{D}$ for the highspin $(S=5 / 2) \mathrm{Mn}(\mathrm{II})$ ion. $\beta_{e}$ and $\beta_{n}$ are the Bohr magneton and nuclear magneton, respectively; $\boldsymbol{g}$ and $g_{n}$ are the electron and nuclear $g$ factors, respectively; $h$ is the Planck constant.

The point-dipole approximation (eq. 2) was used to estimate the dipolar contribution to hyperfine tensor anisotropy $(T=[-T,-T,+2 T])$

$$
\boldsymbol{T}_{d i p}=\frac{\mu_{0}}{4 \pi h} \frac{g \beta_{e} g_{n} \beta_{n}}{r^{3}}
$$

where $\mu_{0}$ is the magnetic vacuum permeability and $r$ is the distance between the two magnetic point dipoles, and other parameters are as defined previously.

\section{Exchangeable Proton Counting}

A published procedure for determining the number of first coordination sphere exchangeable protons was utilized to ascertain the number of water molecules around the $\mathrm{Mn}$ (II) 
center. ${ }^{36,37}$ Three-pulse (3-pulse) ESEEM spectra were collected at a temperature of $10 \mathrm{~K}$ using a microwave frequency of $9.5255(5) \mathrm{GHz}$, and static field strength of $327.35 \mathrm{mT}$ with an $8 \mathrm{~ns} \pi / 2$ pulse. All 3-pulse ESEEM spectra were collected under identical experimental conditions using protein samples prepared in either $\mathrm{H}_{2} \mathrm{O}$ or ${ }^{2} \mathrm{H}_{2} \mathrm{O}$ buffer. In this experiment, a value for $\tau$ was chosen to suppress modulation from protons. ${ }^{38}$ The time domain 3-pulse ESEEM spectrum of $\mathrm{Mn}$ (II)-CP prepared in ${ }^{2} \mathrm{H}_{2} \mathrm{O}$ buffer was divided by that of $\mathrm{Mn}$ (II)-CP prepared in $\mathrm{H}_{2} \mathrm{O}$ buffer. This quotient spectrum contained modulation only from the hyperfine-coupled solvent-exchangeable deuterons.

To determine the number of bound, inner-sphere exchangeable protons, the contribution to the deuterium modulation from weakly-coupled outer-sphere waters must be removed. Two crystal structures of $\mathrm{Mn}$ (II)-bound CP-Ser show that the $\mathrm{Mn}$ (II)-binding site in CP is devoid of outer sphere solvent and thus [Mn(DTPA) $]^{3-}$ is an inappropriate standard (vide infra). Thus, we employed the ${ }^{2} \mathrm{H}_{2} \mathrm{O} / \mathrm{H}_{2} \mathrm{O}$ ratioed spectrum of $\mathrm{Mn}$ (II)-bound CP-Ser (containing 0.9 equivalents $\mathrm{Mn}(\mathrm{II})$ and 10 equivalents $\mathrm{Ca}(\mathrm{II}))$ as the outer-sphere standard instead of $[\mathrm{Mn}(\mathrm{DTPA})]^{3-}$ for all mutants of CP-Ser in order to ascertain whether any change in the hydration level of the $\mathrm{Mn}$ (II) ion results from mutation of the $\mathrm{Mn}$ (II)-coordinating ligands of the S100A9 C-terminal tail.

Changes in the deuteron modulation depth upon mutation of CP-Ser can be understood in terms of an increase in the number of first-coordination sphere waters or hydroxides by comparison to a standard spectrum of $\left[\mathrm{Mn}\left(\mathrm{H}_{2} \mathrm{O}\right)_{6}\right]^{2+}$. The modulation depth of $\left[\mathrm{Mn}\left({ }^{2} \mathrm{H}_{2} \mathrm{O}\right)_{6}\right]^{2+} /\left[\mathrm{Mn}\left(\mathrm{H}_{2} \mathrm{O}\right)_{6}\right]^{2+}$ further divided by the ${ }^{2} \mathrm{H}_{2} \mathrm{O} / \mathrm{H}_{2} \mathrm{O}$ ratioed spectrum of $[\mathrm{Mn}(\mathrm{DTPA})]^{3-}$ corresponds to six bound water molecules (12 deuterons). Fewer than 12 deuterons are interpolated from the hexaquamanganese spectrum by taking the ${ }^{12} \mathrm{~V}_{\mathrm{n}}$ of the spectrum where $\mathrm{n}$ is the number of deuterons. ${ }^{39}$

\section{Results and Discussion}

\section{X-Ray Crystal Structure of a 1:1 Mn(II)-CP Complex}

$\mathrm{CP}$ has the ability to exist in a variety of metal-bound forms, $, 9,10,13,18$ making structural elucidation of different CP species necessary for understanding its coordination chemistry and biological function. Despite its propensity to bind $\mathrm{Ca}(\mathrm{II})$ and transition metal ions in varying ratios, as well as the significance of $\mathrm{M}(\mathrm{II})-\mathrm{CP}$ in the immune response, prior to this work only two crystal structures of metal-bound $\mathrm{CP}$ were available in the Protein Data Bank (PDB) with accession codes $1 \mathrm{XK} 4$ and $4 \mathrm{GGF} .{ }^{13,18}$ For this investigation, we sought to obtain a crystal structure of $\mathrm{Ca}(\mathrm{II})$ - and $\mathrm{Mn}$ (II)-bound CP-Ser in conditions comparable to those employed for pulse EPR spectroscopic characterization to confirm that $\mathrm{Mn}$ (II) is coordinated only in the $\mathrm{His}_{6}$ site. On the basis of our initial Mn(II)-binding studies, which revealed that site 2 is the high-affinity $\mathrm{Mn}(\mathrm{II})$ binding site $\left(K_{\mathrm{d}}\right.$, site $1=21 \pm 5 \mu \mathrm{M} ; K_{\mathrm{d} \text {, site } 2=}=$ $194 \pm 203 \mathrm{nM}$; in the presence of 40 equivalents of $\mathrm{Ca}(\mathrm{II})$ as ascertained by RT-EPR), ${ }^{2,10}$ we expected that incubation of CP-Ser with 1.0 equivalent of $\mathrm{Mn}$ (II) would result in the metal ion only populating the $\mathrm{His}_{6}$ site. We therefore crystallized $\mathrm{Ca}$ (II)- and $\mathrm{Mn}$ (II)-bound CP-Ser using a 10:1:1 ratio of $\mathrm{Ca}(\mathrm{II}): \mathrm{Mn}(\mathrm{II})$ :CP-Ser. The resulting structure is presented in Figure 1. Consistent with our expectations, these conditions afford only one $\mathrm{Mn}$ (II) ion bound to each CP-Ser heterodimer. The electron density and anomalous density maps 
(Figure 1C-E) indicate that $\mathrm{Mn}$ (II) is coordinated only by the high-affinity $\mathrm{His}_{6}$ site comprised of His17 and His27 from S100A8 and His91, His95, His103 and His105 from S100A9. The structural attributes of this octahedral Mn(II)-binding site are in excellent agreement with structurally characterized small-molecule $\mathrm{Mn}$ (II) hexaimidazole complexes $^{40-45}$ as well as a recently reported structure of Mn(II)-bound CP-Ser (PDB 4GGF) (Tables S4 and S5). ${ }^{13}$ In contrast to the 4GGF structure, which revealed Mn(II) bound to the $\mathrm{His}_{3} \mathrm{Asp}$ site with $50 \%$ occupancy in three of the four heterodimers of the asymmetric unit, our crystallization conditions result in no electron density corresponding to a bound metal ion at the low-affinity Mn(II) site (Figure 1C). The transition-metalcoordinating residue (A9)His20 is flipped away from the position it needs to be in to coordinate $\mathrm{Mn}$ (II) consistent with the CP crystal structure without Mn(II) (PDB 1XK4) (Figure S2). The side chain of (A8)His87 is poorly defined in the electron density map, indicating that the $\mathrm{C}$-terminal region of S100A8 is disordered in the absence of a coordinating transition metal (Figure 1C).

Including 10 equivalents of $\mathrm{Ca}$ (II) in the crystallization conditions yielded electron density consistent with $\mathrm{Ca}(\mathrm{II})$ bound to each of the two canonical C-terminal EF-hand domains. Initially, we modeled the non-canonical S100A8 and S100A9 N-terminal EF-hands of each heterodimer with $\mathrm{Ca}$ (II) ions present with occupancies of $50 \%$ and $70 \%$, respectively. In the 1XK4 structure of $\mathrm{Ca}$ (II)-bound calprotectin, $\mathrm{Ca}(\mathrm{II})$ ions in the non-canonical EF-hand were modeled in at $70 \%$ occupancy. ${ }^{18}$ In the prior Mn(II)-CP structure (PDB 4GGF), for which stoichiometric $\mathrm{Ca}$ (II) was employed in the crystallization conditions, $\mathrm{Ca}$ (II) was modeled in the S100A9 non-canonical EF-hand site at 100\% occupancy, and the S100A8 non-canonical EF-hand has a water molecule modeled into the site. ${ }^{13}$ To further investigate the origins of the electron density in the non-canonical EF-hand domains of the present structure, a dataset collected using our in-house $\mathrm{X}$-ray source was examined. The wavelength at the $\mathrm{Cu}-\mathrm{K}$ edge $(\lambda=1.54 \AA$ ) allows for detection of anomalous signals from both $\mathrm{Mn}(\mathrm{II})$ and $\mathrm{Ca}(\mathrm{II})$, and the intensity of the manganese anomalous signal is expected to be approximately twice that of the calcium anomalous signal. Using these data, we observe the presence of anomalous density consistent with $\mathrm{Mn}(\mathrm{II})$ in the $\mathrm{His}_{6}$ site and $\mathrm{Ca}(\mathrm{II})$ in the canonical C-terminal EFhand domains of each S100 subunit (Figures 1E and S4). In contrast, no anomalous density is observed in the non-canonical EF-hand domains located in the N-terminal regions of S100A8 and S100A9 (Figures 1E and S4). Sodium is present in ca. 1000-fold excess relative to $\mathrm{CP}-\mathrm{Ser}$ in the protein and crystallization buffers, and $\mathrm{Na}(\mathrm{I})$ does not give rise to anomalous scattering. Thus, to best fit the electron density, $\mathrm{Na}(\mathrm{I})$ was modeled into both the S100A8 and S100A9 non-canonical N-terminal EF-hand sites at 100\% occupancy. This analysis suggests that excess $\mathrm{Na}$ (I) outcompetes $\mathrm{Ca}$ (II) at the non-canonical EF-hands under the crystallization conditions. The $\mathrm{Ca}(\mathrm{II})$ - and $\mathrm{Na}(\mathrm{I})$-ligand distances for the $\mathrm{CP}$ EF-hands are listed in Table S6.

Although the number of metal ions in the three available CP heterotetramer crystal structures differ, the global tertiary structure is unaltered by $\mathrm{Mn}$ (II) coordination. The average RMSD between the Ca carbons of the crystal structure of the $\mathrm{Ca}$ (II)-bound CP-Ser heterotetramer (PDB 1XK4) ${ }^{18}$ and the structure reported in the present work is $0.42 \AA$, and the variations primarily arise from ordering of the $\mathrm{C}$-terminal tail regions of S100A9 in the presence of $\mathrm{Mn}(\mathrm{II})$ (Figure S2). The RMSD between the Ca carbons of the prior $\mathrm{Ca}(\mathrm{II})$ - and 
Mn(II)-bound CP-Ser heterotetramer (PDB 4GGF) ${ }^{13}$ and the current structure is $0.21 \AA$ (Figure S3). These comparisons indicate that $\mathrm{Mn}$ (II) coordination has a minimal effect on the overall secondary and tertiary structure of $\mathrm{CP}$ in the presence of $\mathrm{Ca}(\mathrm{II})$.

Our refinement indicates that the $\mathrm{Mn}$ (II)-His 6 site excludes solvent water from the primary coordination sphere, resulting in a remarkably dry $\mathrm{Mn}$ (II) coordination environment. Furthermore, there are hydrogen bonding interactions between the Mn(II)-coordinating His residues and additional protein side chains. We hypothesize that these interactions limit water in the secondary coordination sphere. Indeed, only two ordered water molecules are observed in the secondary coordination sphere of $\mathrm{Mn}$ (II) at site 2 (Figure 2). The atoms (A9)His91 N $\delta 1$ and (A9)His103 N $\delta 1$ each form a hydrogen-bonding interaction with these ordered solvent water molecules. Additionally, (A8)His $17 \mathrm{~N} 81$ forms a hydrogen bond with the backbone carbonyl of (A8)Ile13, and (A9)His95 N 81 forms a hydrogen bond with (A9)Asp98. The atom (A8)His27 N 81 forms a hydrogen bond at the dimer-dimer interface with Asp65 from the second S100A9 polypeptide chain (Figure 2). These hydrogen-bonding interactions may contribute to the thermodynamic stability of $\mathrm{Mn}$ (II)- and $\mathrm{Ca}$ (II)-bound $\mathrm{CP}$ as well as charge neutralization at the $\mathrm{His}_{6}$ site.

\section{Mn(II) X-Band CW EPR of CP-Ser and Mutant Proteins in the Presence of $\mathrm{Ca}$ (II)}

The CW EPR spectrum of Ca(II)- and Mn(II)-bound CP-Ser (75 mM HEPES, $100 \mathrm{mM}$ $\mathrm{NaCl}, \mathrm{pH} 7.5,10$ equiv. of $\mathrm{Ca}(\mathrm{II}))$ was previously reported, and the Spincount simulation ( $D$ $=270 \mathrm{MHz}, E / D=0.30$, Table 2) indicated a nearly idealized octahedral Mn(II)

coordination sphere. ${ }^{10}$ In the current work, we further probed the $\mathrm{Mn}$ (II) coordination sphere of CP-Ser and select metal-binding site mutants using CW and pulse EPR spectroscopies. The EPR samples were prepared with 0.9 equivalents of $\mathrm{Mn}$ (II) and 10 equivalents of $\mathrm{Ca}(\mathrm{II})$. Under these conditions, we expect that $\mathrm{Mn}(\mathrm{II})$ is bound only at the $\mathrm{His}_{6}$ site and all four $\mathrm{EF}-$ hand domains contain $\mathrm{Ca}(\mathrm{II})$ or $\mathrm{Na}(\mathrm{I})$, as seen in the crystal structure presented in Figure 1. Representative low temperature $(10 \mathrm{~K}) \mathrm{X}$-band $(9.4 \mathrm{GHz}) \mathrm{CW}$ EPR spectra of CPSer, and the $\Delta \mathrm{His}_{3} \mathrm{Asp}$ and H103A mutants are presented in Figure 3. Additional spectra of $\mathrm{CP}$ mutants are presented in Figure S5.

The isotropic $g$-value of 2.001 observed for these samples is typical for high-spin $d^{5} \mathrm{Mn}$ (II) ions and results from the near-spherical symmetry of the electron spin distribution around the $\mathrm{Mn}$ (II) center. The sextet of EPR features centered at $g=2.001$ arises from the hyperfine coupling of the ${ }^{55} \mathrm{Mn}$ nucleus ( $I=5 / 2,100 \%$ abundance) with the $m_{s}= \pm 1 / 2$ electron spin manifolds. The hyperfine-induced splitting of the four outer manifold $\left(m_{s}= \pm 1 / 2 \leftrightarrow m_{s}=\right.$ $\pm 3 / 2$ and $m_{s}= \pm 3 / 2 \leftrightarrow m_{s}= \pm 5 / 2$ ) EPR transitions is rarely resolved in spectra of frozen solutions because of the orientation-dependent spectral broadening of EPR transitions in these spin manifolds. ${ }^{51,52}$ The spectra in Figure 3 reveal that both CP-Ser and $\Delta \mathrm{His}_{3} \mathrm{Asp}$ samples exhibit identical Mn(II) spectroscopic signatures. This result is in agreement with prior work ${ }^{10}$ and indicates that there is no $\mathrm{Mn}$ (II) coordinated by site 1 under these conditions. For CP-Ser and the $\Delta \mathrm{His}_{3} \mathrm{Asp}$ mutant, the hyperfine coupling to the ${ }^{55} \mathrm{Mn}$ nucleus was found to be isotropic with a magnitude of $247 \mathrm{MHz}$. This value is low relative to published values; reported ${ }^{55} \mathrm{Mn}$ hyperfine coupling values are typically $>255$ MHz. ${ }^{47,53-55}$ The low coupling constant is consistent with the high number of His ligands 
and the reported trend of decreased ${ }^{55} \mathrm{Mn}$ hyperfine coupling as more imidazoles are bound to a $\mathrm{Mn}$ (II) ion. ${ }^{53}$ Between each pair of lines of the sextet lie two formally forbidden $\Delta m_{s}=$ $\pm 1, \Delta m_{I}= \pm 1$ transitions. By paying particular attention to the ratio of the intensity of the forbidden EPR transitions to that of the allowed EPR transitions, as well as the overall spectral lineshape and width, simulation of the CP-Ser spectrum (Figure 3A) using EasySpin afforded a value for the axial component of the zero-field splitting tensor, $D=485 \mathrm{MHz}$ $(E / D=0.30)$. Although this $D$ value is somewhat larger than the $D$ value obtained previously, ${ }^{10}$ it is still small compared to the reported $D$ values for other Mn(II) complexes (Table 2). A low $D$ value can be indicative of a highly symmetric coordination environment, in accordance with the hexahistidine Mn(II)-binding site observed crystallographically. The $\Delta$ His $_{3}$ Asp spectrum can be simulated using the same parameters as CP-Ser (Figure 3B), which provides further support for the notion that $\mathrm{Mn}$ (II) is exclusively coordinated by the

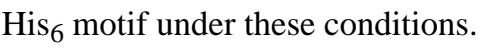

The spectrum of the Mn(II)-H103A mutant reveals that, upon mutation of one of the Mn(II)coordinating His residues to Ala, the intensity of the forbidden transitions relative to the allowed transitions increases significantly (Figure 3C). ${ }^{11}$ This increase in forbidden transition intensity was also seen in the spectra of $\mathrm{CP}$ upon single point mutations of the His $_{4}$ motif. ${ }^{10}$ Such forbidden transitions typically gain intensity as the ZFS increases ${ }^{56}$ In agreement with this observation, simulation of the Mn(II)-H103A signal afforded a $D$ value of $650 \mathrm{MHz}$ (Figure 3C). This $D$ value remains in the range for six-coordinate $\mathrm{Mn}$ (II) $(|D|<$ $3000 \mathrm{MHz}$ ), but suggests that the symmetry of the Mn(II)-binding site has decreased as expected with the loss of one histidine ligand.

\section{Q-Band ENDOR and ESEEM Spectroscopic Studies Confirm a Highly Symmetric Mn(II)- $\mathrm{His}_{6}$ Site in Solution in the Presence of $\mathrm{Ca}(\mathrm{II})$}

Pulse EPR spectroscopy was employed to further characterize the nitrogen atoms of the high-affinity $\mathrm{Mn}(\mathrm{II}) \mathrm{-His}_{6}$ site in the presence of 10 equivalents of $\mathrm{Ca}(\mathrm{II})$. Samples of CP-Ser were globally labeled with ${ }^{15} \mathrm{~N}(I=1 / 2)$-denoted ${ }^{15} \mathrm{~N}-\mathrm{CP}$-Ser-in order to probe only the hyperfine interaction by eliminating the quadrupole interaction intrinsic to the ${ }^{14} \mathrm{~N}(I=1$, $99.6 \%$ abundance) nucleus. The Q-band $(\approx 34.1 \mathrm{GHz})$ Mims-ENDOR spectrum (Figure 4) of $\mathrm{Mn}$ (II)- and $\mathrm{Ca}$ (II)-bound ${ }^{15} \mathrm{~N}-\mathrm{CP}-\mathrm{Ser}$ revealed two sets of doublets centered at the ${ }^{15} \mathrm{~N}$ Larmor frequency (5.3 MHz at $1222.5 \mathrm{mT}$ ). The full hyperfine coupling tensors for the two classes of ${ }^{15} \mathrm{~N}$ nuclei are summarized in Table 3 . We assign the broader, larger spaced doublet (denoted A in Figure 4), simulated with $a_{i s o}=4.36 \mathrm{MHz}$, to ${ }^{15} \mathrm{~N}$ of the proximal histidine nitrogens $(\mathrm{N} \varepsilon 2)$ that directly coordinate $\mathrm{Mn}(\mathrm{II})$. These peaks are artificially split by tau-dependent blind spots intrinsic to Mims-ENDOR (so-called Mims holes), an effect that is verified by collecting the data at different tau values (Figure S6). The narrower, more closely spaced doublet (denoted B) is simulated with the isotropic hyperfine coupling $\left(a_{i s o}\right)$ of $0.24 \mathrm{MHz}$, and is assigned to the distal nitrogen atoms $(\mathrm{N} \delta 1)$ on the imidazole rings. The approximately $18 \mathrm{x}$ larger coupling of $\mathrm{N} \varepsilon 2$ relative to $\mathrm{N} \delta 1$ is consistent with the ratio of proximal-to-distal nitrogen isotropic hyperfine couplings observed in other histidinecoordinated metal systems. ${ }^{57-59}$ The lack of more than two sets of doublets in the ${ }^{15} \mathrm{~N}$ ENDOR spectrum demonstrates the spectroscopic equivalence of the histidine moieties that comprise the Mn(II)-binding site. These couplings are to the central $m_{S}= \pm 1 / 2$ manifolds of 
the $S=5 / 2 \mathrm{Mn}(\mathrm{II})$ ion. Couplings to the higher $m_{S}$ manifolds are weak (see $*$ in Figure 4) and are not analyzed in this work.

The Q-band time domain 3-pulse and 4-pulse ESEEM spectra of ${ }^{15} \mathrm{~N}$-CP-Ser $(+\mathrm{Ca})$ are presented in Figure 5A. These ${ }^{15} \mathrm{~N}$ ESEEM spectra are well simulated using the coupling constants derived from the above ENDOR spectroscopic study (Figure 4). The corresponding Fourier transform of the 4-pulse ESEEM data is presented in Figure 5B. The ${ }^{15} \mathrm{~N}$ transitions of the coordinating imidazole nitrogen atoms are the pair of features centered at 3.1 and $7.5 \mathrm{MHz}$. The sharp peak at $10.6 \mathrm{MHz}$ results from the sum of these two fundamental ${ }^{15} \mathrm{~N}$ frequencies. This combination peak is naturally sharper than the fundamental peaks because orientation dependences in each fundamental peak are nulled in the sum combination peak. ${ }^{60}$ The modulation in the 4-pulse ESEEM spectrum is remarkably long-lived (>19 $\mu \mathrm{sec}$ ) and indicative of well-defined and equivalent ${ }^{15} \mathrm{~N}$ frequencies from the six coordinating $\mathrm{N} \varepsilon 2$ ligands.

In addition to globally labeled ${ }^{15} \mathrm{~N}$-CP-Ser, we prepared mixed-labeled samples of $\Delta \mathrm{His}_{3} \mathrm{Asp}$ where only one subunit was ${ }^{15} \mathrm{~N}$-labeled. We accomplished this labeling scheme by expressing one S100A8/S100A9 subunit in minimal medium containing ${ }^{15} \mathrm{~N}$ ammonium chloride as the sole nitrogen source and the other subunit in minimal medium with nitrogen at natural abundance. This procedure provided a set of samples with zero ${ }^{15} \mathrm{~N}$ (a natural abundance sample), two ${ }^{15} \mathrm{~N}\left({ }^{15} \mathrm{~N}(\mathrm{~A} 8)-\Delta \mathrm{His}_{3} \mathrm{Asp}\right)$, four ${ }^{15} \mathrm{~N}\left({ }^{15} \mathrm{~N}(\mathrm{~A} 9)-\Delta \mathrm{His}_{3} \mathrm{Asp}\right)$, and six ${ }^{15} \mathrm{~N}\left({ }^{15} \mathrm{~N}-\Delta \mathrm{His}_{3} \mathrm{Asp}\right)$ derived from ${ }^{15} \mathrm{~N}$-labeled His residues contributing to the $\mathrm{Mn}$ (II) coordination sphere. The 4-pulse ESEEM Fourier transformation for each of these four samples are shown in Figure 6. The inset shows an approximately linear trend in the amplitude of the combination ${ }^{15} \mathrm{~N}$ peak at $10.6 \mathrm{MHz}$ with respect to the number of ${ }^{15} \mathrm{~N}$ nitrogen ligands. Hyperfine sublevel correlation (HYSCORE) spectra of fully and partially ${ }^{15} \mathrm{~N}$-labeled species are presented in Figures S7-S10.

\section{Exchangeable Proton Counting Reveals that the C-Terminal Tail of S100A9 Prevents Water Access to Bound Mn(II)}

The amino acid sequence of the C-terminal tail, defined as residues 96-114 of S100A9, is EGDEGPGHHHKPGLGEGTP where the Mn(II)-coordinating His103 and His105 residues are shown in boldface. The crystal structure of the $\mathrm{Ca}$ (II)-bound $\mathrm{CP}$-Ser heterotetramer (PDB 1XK4) revealed a disordered tail region, indicating that the tail is dynamic in the absence of Mn(II). ${ }^{18}$ We previously characterized the Mn(II)-binding properties and antimicrobial activity of a mutant family to probe the consequences of perturbation of the HXH motif on CP function, ${ }^{11}$ and hypothesized that solvent water may contribute to $\mathrm{Mn}$ (II) coordination in the absence of His 103 and/or His105. To evaluate this notion, we employed 3-pulse ESEEM spectroscopy to determine the number of exchangeable deuterons in the immediate vicinity of the Mn(II) ion bound to H103A, H104A, H105A, AHA, and AAA mutants of $\mathrm{CP}$ in the presence of 10-fold $\mathrm{Ca}$ (II) (see the Experimental section for details on this procedure). In previous water-counting studies using ${ }^{2} \mathrm{H}_{2} \mathrm{O}$-enriched buffer, we employed $[\mathrm{Mn}(\mathrm{DTPA})]^{3-}($ DTPA $=$ diethylaminetriaminepentaacetic acid $)$ as a spectroscopic standard for Mn(II) with zero bound water because the hexacoordinate DTPA chelating ligand excludes water from the first coordination sphere of manganese ${ }^{36,37,61}$ 
however, the outer sphere is fully exposed to solvent ${ }^{2} \mathrm{H}_{2} \mathrm{O}$. Figure 7 compares the ${ }^{2} \mathrm{H}_{2} \mathrm{O} / \mathrm{H}_{2} \mathrm{O}$ ratioed 3-pulse ESEEM spectra, which eliminates contributions from other magnetic nuclei such as ${ }^{14} \mathrm{~N}$, of $\mathrm{Mn}$ (II)-bound $\mathrm{CP}$ and [Mn(DTPA) $]^{3-}$. The ${ }^{2} \mathrm{H}$ modulation of $\mathrm{Mn}(\mathrm{II})-\mathrm{CP}$ is appreciably weaker than that of the DTPA chelate, demonstrating that the $\mathrm{Mn}(\mathrm{II})$ has no inner sphere waters and that its hexahistidine site is shielded from ${ }^{2} \mathrm{H}$ exchange into the outer sphere as well. A simulation using a dipolar coupling of $0.26 \mathrm{MHz}$ $\left(\mathrm{r}=3.6 \AA\right.$ ) partially reproduces the persistent ${ }^{2} \mathrm{H}$ modulation in the ${ }^{2} \mathrm{H}_{2} \mathrm{O} /{ }^{1} \mathrm{H}_{2} \mathrm{O}$ ratioed 3pulse ESEEM spectrum of CP-Ser. Further evidence for the absence of inner-sphere exchangeable deuterons in CP-Ser is provided by the proton Davies ENDOR spectra of $\mathrm{Mn}$ (II)- and $\mathrm{Ca}$ (II)-bound CP-Ser in $\mathrm{H}_{2} \mathrm{O}$ and ${ }^{2} \mathrm{H}_{2} \mathrm{O}$ buffer (Figure S11). A comparison of these spectra reveals that exchanging $\mathrm{Mn}(\mathrm{II})$ - and $\mathrm{Ca}$ (II)-bound CP-Ser into ${ }^{2} \mathrm{H}_{2} \mathrm{O}$ buffer has only a modest effect on the ${ }^{1} \mathrm{H}$ ENDOR spectrum, decreasing the intensity only at the ${ }^{1} \mathrm{H}$ Larmor frequency, which indicates that only weakly coupled and distant protons are replaced. Thus, the pulse EPR results of $\mathrm{Mn}(\mathrm{II})$ - and $\mathrm{Ca}(\mathrm{II})$-bound $\mathrm{CP}-\mathrm{Ser}$ in solution are consistent with the dry $\mathrm{Mn}(\mathrm{II})$ environment revealed in our X-ray structure, which was obtained at comparable $\mathrm{Mn}(\mathrm{II})$ and $\mathrm{Ca}(\mathrm{II})$ concentrations (Figure 2).

We next examined the effect of mutating histidine ligands of the S100A9 tail region on the hydration of the $\mathrm{Mn}$ (II) center. The double ratioed $\left({ }^{2} \mathrm{H}_{2} \mathrm{O} / \mathrm{H}_{2} \mathrm{O}\right.$ [mutant $] /{ }^{2} \mathrm{H}_{2} \mathrm{O} / \mathrm{H}_{2} \mathrm{O}$ [CPSer]) ESEEM spectra are shown in Figure 8. This presentation emphasizes the changes induced by the specific mutation. Standard modulation curves for 1 through 4 inner sphere deuterons are provided (see Experimental Section). H104 does not coordinate Mn(II) and, as expected, the H104A mutant shows no additional deuteron modulation relative to the inner sphere deuteron standards. Mutations at the two tail histidine ligand sites introduce appreciable ${ }^{2} \mathrm{H}$ modulation, with approximately one inner sphere deuteron appearing in the H105A mutant and close to two inner sphere deuterons appearing in the H103A mutant. Furthermore, the AHA and AAA mutants, both of which lack the Mn(II)-coordinating His residues of the tail, show deep deuteron modulation, consistent with three inner sphere deuterons. Compared to the shallow and persistent ${ }^{2} \mathrm{H}$ modulation of $\mathrm{CP}-\mathrm{Ser}$, the inner sphere ${ }^{2} \mathrm{H}$ modulation damps quickly in the time domain, corresponding to wider peaks in the Fourier transform (not shown) due to the stronger dipolar hyperfine couplings. We conclude that in the absence of the histidine ligands from the tail, water and/or hydroxide can access the $\mathrm{Mn}(\mathrm{II})$ inner coordination sphere.

A decrease in symmetry of the $\mathrm{Mn}$ (II) center will result from loss of a native histidine ligand and occupation of the vacant $\mathrm{Mn}$ (II) coordination site with a water molecule or hydroxide ion. Indeed, the CW EPR spectra of the H103A and H105A mutants (Figures 3 and S4) indicate that the symmetry of the $\mathrm{Mn}$ (II)-binding site has been dramatically lowered with loss of a histidine ligand, as supported by a significant increase in the magnitude of the ZFS interaction. Simulation of the CW EPR data for the H103A mutant yielded a $D$ value of approximately $650 \mathrm{MHz}$ (Table 2). For the spectrum of the H105A mutant, a value of $D$ could not be determined as a result of the more complex line shape; however, the ratio of the allowed EPR transition intensity to that of the forbidden transitions is diminished compared to that observed in the spectrum of the H103A mutant, which indicates that the Mn(II) bound to H105A CP-Ser (Figure S4) has the highest ZFS of the single point mutants we 
investigated (> $650 \mathrm{MHz}$ ). Thus, based on the ZFS parameters discerned from analysis of the CW EPR spectra of the CP mutants, the Mn(II) ion coordination environment becomes less symmetric according to the trend CP-Ser > H103A > H105A with the H105A mutant exhibiting the lowest symmetry.

The ESEEM and CW EPR data together establish that the Mn(II) ion at the $\mathrm{His}_{6}$ site becomes solvent exposed in the absence of His 103 and/or His105. The direct demonstration of increased solvent accessibility upon mutating residues of the His ${ }_{6}$ site is important for understanding the ability of $\mathrm{CP}$ to sequester labile $\mathrm{Mn}(\mathrm{II})$. Our results are consistent with a model where encapsulation of $\mathrm{Mn}$ (II) by the C-terminal tail of S100A9 is essential for metal sequestration, and that solvent exposure makes the $\mathrm{Mn}(\mathrm{II})$ ion more kinetically labile. Although the AHA and AAA mutants retain the ability to bind Mn(II), these mutants are unable to sequester $\mathrm{Mn}(\mathrm{II}){ }^{11}$

We note that capture of $\mathrm{Mn}$ (II) at the $\mathrm{His}_{6}$ site of $\mathrm{Ca}$ (II)-bound $\mathrm{CP}$ is reminiscent of synthetic small-molecule cages designed to coordinate first-row transition metal ions with high affinity. In particular, the sarcophagines are macrobicyclic hexa-amine ligands that encapsulate labile metal ions, including high-spin $\mathrm{Mn}(\mathrm{II}){ }^{62,63}$

\section{Mn(II) Binding to CP-Ser is Promiscuous in the Absence of $\mathrm{Ca}$ (II)}

Because the $\mathrm{Mn}$ (II)-chelating properties of $\mathrm{CP}$ are $\mathrm{Ca}$ (II)-dependent, we next applied EPR to further characterize $\mathrm{Mn}$ (II)-CP in the absence of $\mathrm{Ca}$ (II) with the goal of ascertaining whether changes in the $\mathrm{Mn}$ (II) electronic/geometric structure or speciation occur. In prior work, we concluded that CP-Ser (-Ca) binds Mn(II) with micromolar affinity at site $2\left(K_{\mathrm{d}}\right.$, site $2=4.9$ $\pm 1.0 \mu \mathrm{M}$, determined by RT-EPR titrations). ${ }^{10}$ These studies also demonstrated that the interfacial $\mathrm{His}_{4}$ motif of site 2 is required for appreciable $\mathrm{Mn}$ (II) complexation in the absence of $\mathrm{Ca}$ (II). ${ }^{10}$ On the basis of the observed micromolar Mn(II) affinity of CP-Ser (-Ca), and to minimize free $\mathrm{Mn}$ (II) in the sample, we prepared a Mn(II):CP sample with 180 $\mu \mathrm{M} \mathrm{Mn(II)} \mathrm{and} \mathrm{1.0} \mathrm{mM} \mathrm{CP-Ser} \mathrm{(vide} \mathrm{infra).}$

In agreement with our prior work, ${ }^{10,11}$ the low-temperature X-band CW EPR spectra of $\mathrm{Mn}(\mathrm{II})-\mathrm{CP}-\mathrm{Ser}$ in the presence and absence of excess $\mathrm{Ca}(\mathrm{II})$ markedly differ (Figures 3A and 9A). In the absence of $\mathrm{Ca}(\mathrm{II})$, all of the spectral features for $\mathrm{Mn}$ (II) appear to broaden significantly. When the - $\mathrm{Ca}$ (II) sample was buffer exchanged into buffer prepared with ${ }^{2} \mathrm{H}_{2} \mathrm{O}$, sharpening of some features occurred (traces A and B in Figure 9). This observation is consistent with significant hyperfine interactions between the $\mathrm{Mn}$ (II) and solvent-exchangeable hydrogen. Moreover, in the spectrum of the - $\mathrm{Ca}$ (II) sample prepared in ${ }^{2} \mathrm{H}_{2} \mathrm{O}$, the lowest-field member of the $\mathrm{Mn}$ (II) sextet centered at $-25 \mathrm{mT}$ is clearly split (Figure 9B), which suggests that at least two magnetically distinct Mn(II)-containing species contribute to the EPR spectrum in this region. This splitting can be approximately modeled by a linear combination of the ${ }^{2} \mathrm{H}_{2} \mathrm{O}$-exchanged $\mathrm{Mn}$ (II)- and Ca(II)-bound CP-Ser spectrum (Figure 9C) and a spectrum of $\left[\mathrm{Mn}\left({ }^{2} \mathrm{H}_{2} \mathrm{O}\right)_{6}\right]^{2+}$ (Figure 9D) in a 1:1 ratio (Figure 9B, gray trace).

In order to further evaluate the $\mathrm{Mn}$ (II) speciation in the -Ca(II) sample, room-temperature EPR (RT-EPR) was employed to quantify the amount of unbound $\mathrm{Mn}$ (II) in the sample. 
Whereas $\left[\mathrm{Mn}\left(\mathrm{H}_{2} \mathrm{O}\right)\right]^{2+}$ gives a six-line pattern centered at $g=2$ at room temperature, $\mathrm{Mn}(\mathrm{II})$ coordinated by macromolecules does not give rise to a detectable signal. Furthermore, the RT-EPR Mn(II) signal is quantitative and allows for the concentration of unbound $\mathrm{Mn}$ (II) to be determined. ${ }^{64,65}$ Analysis of the 0.18:1.0 Mn(II):CP-Ser prepared in the absence of Ca(II) revealed a RT-EPR signal that accounted for ca. 10-20\% (20-40 $\mu \mathrm{M})$ of the total $\mathrm{Mn}$ (II) (Figure S12). We note that the observed quantity of free $\mathrm{Mn}(\mathrm{II})$ is greater than the expected amount calculated by using a $K_{\mathrm{d}}$ value of $\approx 5 \mu \mathrm{M}$ that was determined for CP-Ser (-Ca) by RT-EPR. The amount of free Mn(II) concentration increased to approximately $50 \%$ of the total when 0.9 equiv of $\mathrm{Mn}$ (II) was added to CP-Ser in the absence of $\mathrm{Ca}$ (II) (Figure S12). On the basis of this quantification, and to minimize the free $\mathrm{Mn}$ (II) signal, we decided to further investigate $\mathrm{Mn}(\mathrm{II})$ complexation by $\mathrm{CP}-\mathrm{Ser}$ in the absence of added $\mathrm{Ca}(\mathrm{II})$ using samples prepared with 0.18:1 Mn(II):CP-Ser.

In prior Mn(II)-binding studies of CP-Ser, the inclusion of additional low-affinity (1.0 mM) Mn(II)-binding events was necessary to fit the RT-EPR Mn(II) titration curve. This analysis indicated the presence of additional $\mathrm{Mn}$ (II)-binding sites in the absence of $\mathrm{Ca}$ (II). To investigate this possibility, the speciation of $\mathrm{Mn}$ (II)-CP (-Ca) was interrogated by pulse EPR. The 4-pulse ESEEM Fourier transforms of ${ }^{15} \mathrm{~N}-\mathrm{CP}-\mathrm{Ser}$ in the presence and absence of $\mathrm{Ca}$ (II) are compared in Figure 10. The lineshapes of the ${ }^{15} \mathrm{~N}$ ESEEM and ENDOR (Figures 10 and 11, respectively) are the same for $-\mathrm{Ca}$ and $+\mathrm{Ca}$ samples, showing there is no new or different nitrogen coordination to $\mathrm{Mn}(\mathrm{II})$ in the absence of $\mathrm{Ca}$ (II). Nevertheless, the ${ }^{15} \mathrm{~N}$ pulse ESEEM combination peak amplitude of $\mathrm{Mn}$ (II)-CP (-Ca) corresponds to only ca. 2.6 nitrogens per Mn(II) (Figure 6 inset). This observation supports our analysis of the lowtemperature CW EPR spectra (Figure 9) in that ca. $50 \%$ of the $\mathrm{Mn}$ (II) is coordinated by the $\mathrm{His}_{6}$ site in the absence of $\mathrm{Ca}$ (II) in this sample containing a 0.18:1 Mn(II):CP-Ser molar ratio. An analysis of the natural abundance ${ }^{14} \mathrm{~N}$ modulation in 3-pulse ESEEM data also supports this conclusion (vide infra).

Next, the degree of hydration of the Mn(II) site(s) in the absence of $\mathrm{Ca}(\mathrm{II})$ was assessed by ESEEM as described for the $+\mathrm{Ca}$ (II) samples. Consistent with prior observations, the hydration level increases with increasing $\mathrm{Mn}$ (II) in the - $\mathrm{Ca}$ (II) samples. Indeed, the samples prepared with 0.18:1.0 and 0.9:1.0 $\mathrm{Mn}(\mathrm{II})$ :CP-Ser ratios have approximately one and two exchangeable protons, respectively (Figure 12). The ${ }^{2} \mathrm{H}_{2} \mathrm{O} / \mathrm{H}_{2} \mathrm{O}$ ratioed 3-pulse ESEEM, spectrum of CP-Ser (-Ca) with 0.18 equivalents of $\mathrm{Mn}$ (II) shows a significant increase in the amount of residual ${ }^{2} \mathrm{H}$ modulation compared to that for the corresponding $+\mathrm{Ca}$ (II) sample (Figure 13). This deuterium modulation can be accounted for by scaling the ${ }^{2} \mathrm{H}_{2} \mathrm{O} / \mathrm{H}_{2} \mathrm{O}$ ratioed 3-pulse ESEEM spectrum of aqueous $\mathrm{Mn}$ (II) to correspond to $12 \%$ of the total $\mathrm{Mn}$ (II) concentration. This value is within the $10-20 \%$ range of unbound $\mathrm{Mn}$ (II) predicted by our RT-EPR analysis (Figure S12). Thus, all inner-sphere water detected in the ratioed ESEEM spectrum can be accounted for by the fraction of aqueous $\mathrm{Mn}$ (II) in the $-\mathrm{Ca}$ sample.

In total, these data suggest that $\mathrm{Mn}$ (II) binds to several different sites in $\mathrm{CP}$ when $\mathrm{Ca}$ (II) is omitted from the buffer. For a 1.0 mM CP-Ser (-Ca) sample containing $180 \mu \mathrm{M} \mathrm{Mn}$ (II), we determine that $\approx 90 \mu \mathrm{M}$ of the $\mathrm{Mn}$ (II) is coordinated by the $\mathrm{His}_{6}$ site and $20-40 \mu \mathrm{M}$ exists as aqueous Mn(II). Because no new features are observed in either the ${ }^{15} \mathrm{~N}$ 4-pulse ESEEM or 
the Mims ENDOR spectra (Figures 10 and 11) as a result of omitting $\mathrm{Ca}(\mathrm{II})$ from the $\mathrm{Mn}(\mathrm{II})-\mathrm{CP}$ sample, the remainder of $\mathrm{Mn}(\mathrm{II})(\approx 50-70 \mu \mathrm{M})$ must be bound to a site (or sites) that do not contain nitrogen ligands. Furthermore, the additional Mn(II)-binding site(s) appears to coordinatively saturate the $\mathrm{Mn}(\mathrm{II})$ ion as there is no ${ }^{2} \mathrm{H}$ modulation in the ${ }^{2} \mathrm{H}_{2} \mathrm{O} / \mathrm{H}_{2} \mathrm{O}$ ratioed 3-pulse ESEEM spectrum of the - $\mathrm{Ca}$ (II) sample that cannot be attributed to the modest amount of aqueous $\mathrm{Mn}$ (II) observed by RT-EPR spectroscopy.

Candidates for the additional Mn(II) sites include site 1 (His 3 Asp) and the EF-hand domains. The previous $\mathrm{Mn}$ (II)-bound crystal structure (PDB ID 4GGF), obtained with $\mathrm{Ca}$ (II) present in the crystallization conditions, showed $\mathrm{Mn}$ (II) bound at Site 1 in a 5-coordinate geometry with a bidentate interaction from Asp30. ${ }^{13}$ Pentacoordinate Mn(II) sites are characterized by large zero-field splittings ( $D$ is typically greater than $3000 \mathrm{MHz}$ ) and give rise to distinct EPR spectra. ${ }^{50,66,67} \mathrm{We}$ see no such evidence for such spectroscopic features in the CW EPR spectrum of the - $\mathrm{Ca}$ (II) sample. Nevertheless, simulations of $\mathrm{Mn}$ (II) EPR spectra with ZFS values ranging from 1,000 to $10,000 \mathrm{MHz}$, along with a representative $\mathrm{Mn}$ (II) spectrum with a ZFS of $500 \mathrm{MHz}$ indicate that detecting a high-ZFS species in the presence of the $\mathrm{Mn}(\mathrm{II})-\mathrm{His}_{6}$ signal is difficult (Figure S14).

The EF-hand domains provide multi-dentate coordination spheres comprised of oxygen donor atoms (Table 1), and select EF-hand domains are reported to chelate $\mathrm{Mn}(\mathrm{II}){ }^{68,69}$ For instance, a crystal structure of the N-terminal domain of calmodulin crystallized in the presence of $\mathrm{Mn}$ (II) revealed an octahedral $\mathrm{Mn}$ (II) center where the primary coordination sphere includes two solvent water molecules. ${ }^{69}$ In prior work, we suggested that $\mathrm{Mn}$ (II) may associate with the vacant EF-hand domains of CP-Ser with low affinity ${ }^{10}$ and our current investigation provides additional support for $\mathrm{Mn}$ (II) binding in such coordination environments. Indeed, the ligand framework provided by an EF-hand domain is expected to give rise to a $\mathrm{Mn}$ (II) $\mathrm{CW}$ EPR spectrum with similar $g$ and $\mathbf{A}$ values as $\left[\mathrm{Mn}\left(\mathrm{H}_{2} \mathrm{O}\right)_{6}\right]^{2+} .{ }^{47,48,68}$ Although $\mathrm{Mn}$ (II) binding in the His ${ }_{3}$ Asp site remains a possibility on the basis of the current spectroscopic results, we propose that in the absence of $\mathrm{Ca}(\mathrm{II})$, $\mathrm{Mn}(\mathrm{II})$ is coordinated by the $\mathrm{His}_{6}$ site as well as the EF-hand domains of CP-Ser. In prior studies, we observed no Mn(II) binding to CP-Ser- $\Delta \mathrm{His}_{4}$ (site 2 mutant) or $\Delta \Delta$ (site 1 / site 2 mutant) by RT-EPR in the absence of $\mathrm{Ca}(\mathrm{II}) .{ }^{10}$ Thus, we reason that the EF-hand domains cannot bind $\mathrm{Mn}$ (II) to an appreciable degree in the absence of site 2. Taken together with our current proposal, it appears that $\mathrm{Mn}$ (II) chelation at site 2 enhances the $\mathrm{Mn}$ (II) affinity of the EF-hands, which suggests cooperativity between the $\mathrm{His}_{6}$ site and EF-hand domains. Each $\mathrm{CP}$ heterodimer unit harbors four different EF-hand domains, and elucidating the identities of the putative $\mathrm{Mn}$ (II)-binding EF-hands is a subject for future work. On the basis of prior studies $^{68,69}$ and the X-ray crystallographic work presented here, we reason that the Cterminal canonical EF-hands of S100A8 and S100A9 are the most probable sites for Mn(II) binding.

\section{Summary}

In the current work, we address the $\mathrm{Ca}$ (II)-dependent $\mathrm{Mn}$ (II)-binding properties of the human host-defense protein $\mathrm{CP}$, and present crystallographic and EPR spectroscopic characterization of human $\mathrm{CP}$ in the presence of $\mathrm{Mn}(\mathrm{II})$ and $\mathrm{Ca}(\mathrm{II})$. In support of our prior 
solution studies, ${ }^{10}$ the crystal structure presented here confirms that $\mathrm{Mn}(\mathrm{II})$ is coordinated solely at the $\mathrm{His}_{6}$ site when one equivalent of $\mathrm{Mn}(\mathrm{II})$ is present. Anomalous diffraction data establishes that the canonical C-terminal EF-hands coordinate $\mathrm{Ca}(\mathrm{II})$ whereas the noncanonical N-terminal EF-hands are populated by another ion, reasoned to be $\mathrm{Na}(\mathrm{I})$, under crystallographic conditions that included 10 equivalents of $\mathrm{Ca}$ (II). This result is consistent with the low $\mathrm{Ca}(\mathrm{II})$ affinities reported for characterized non-canonical EF-hands, ${ }^{20,22,24,25}$ and further structural and biochemical investigations of $\mathrm{CP}$ to evaluate the interplay between $\mathrm{Ca}(\mathrm{II})$ and $\mathrm{Na}(\mathrm{I})$ are warranted. We note that $\mathrm{S} 100 \mathrm{~A} 2$ and $\mathrm{S} 100 \mathrm{~A} 12$ have also been crystallized and refined with $\mathrm{Na}(\mathrm{I})$ in the non-canonical EF-hands. ${ }^{70,71}$

The application of EPR spectroscopic methods to studies of $\mathrm{CP}$ in the presence of $\mathrm{Ca}$ (II) establishes several important facets about how $\mathrm{CP}$ sequesters $\mathrm{Mn}$ (II) at the $\mathrm{His}_{6}$ site. $\mathrm{Mn}$ (II) is bound to the $\mathrm{His}_{6}$ site with a high degree of electronic symmetry as evidenced by the low $D$ value (Table 2) and in agreement with the symmetric $\mathrm{His}_{6}$ site observed crystallographically. Exchangeable proton counting confirmed that mutation of the S100A9 C-terminal tail perturbs the Mn(II) coordination environment and enables solvent access to the $\mathrm{Mn}(\mathrm{II})$ center. Taken together with our prior studies of the $\mathrm{Mn}$ (II)-chelating properties and antibacterial activity of a C-terminal tail mutant family, we propose that exclusion of water from the primary coordination sphere of the $\mathrm{Mn}$ (II) center is essential for $\mathrm{Mn}$ (II) sequestration. Lastly, pulse EPR spectroscopy enabled further characterization of how the CP-Ser-Ca coordinates Mn(II). Our spectroscopic results demonstrate that (i) CP forms a $\mathrm{Mn}$ (II)-His ${ }_{6}$ coordination sphere at site 2 in the absence of $\mathrm{Ca}$ (II) and (ii) $\mathrm{CP}$ binds $\mathrm{Mn}$ (II) at additional sites in the absence of $\mathrm{Ca}(\mathrm{II})$. We propose that the canonical EF-hands coordinate $\mathrm{Mn}(\mathrm{II})$ under these conditions. CP (-Ca) therefore houses multiple low-affinity Mn(II)binding sites, and the addition of excess $\mathrm{Ca}$ (II) leads to the formation of a single highaffinity $\mathrm{His}_{6}$ coordination site.

\section{Supplementary Material}

Refer to Web version on PubMed Central for supplementary material.

\section{Acknowledgements}

This work was supported by the National Science Foundation (NSF CHE-1352132 to E.M.N.), the National Institutes of Health (NIH 1DP2OD007045-01 to E.M.N.; GM069857 to C.L.D.; F32 GM099257 to S.E.J.B.), the Department of Energy (DE-FG02-11ER16282 to R.D.B.), the Kinship Foundation (Searle Scholar Award to E.M.N.), and the MIT Department of Chemistry. Crystallographic data were collected at the Advanced Photon Source (APS) on the Northeastern Collaborative Access Team beamlines, which are supported by a grant from the NIGMS GM103403 from the National Institutes of Health. APS is also supported by the U.S. Department of Energy under Contract No. DE-AC02-06CH1 1357. C.L.D. is a Howard Hughes Medical Institute Investigator. We thank Michael Funk and Marco Jost for assistance with crystallography and X-ray data collection, and Prof. Stefan Stoll for assistance with the 4p ESEEM simulation.

\section{References}

1. Lisher JP, Giedroc DP. Front. Cell. Infect. Microbiol. 2013; 3:91. [PubMed: 24367765]

2. Brophy MB, Nolan EM. ACS Chem. Biol. 2015 dx.doi.org/10.1021/cb500792b.

3. Kehl-Fie TE, Skaar EP. Curr. Opin. Chem. Biol. 2010; 14:218-224. [PubMed: 20015678]

4. Diaz-Ochoa VE, Jellbauer S, Klaus S, Raffatellu M. Front. Cell. Infect. Microbiol. 2014; 4:2. [PubMed: 24478990] 
5. Papp-Wallace KM, Maguire ME. Annu. Rev. Microbiol. 2006; 60:187-209. [PubMed: 16704341]

6. Kadioglu A, Weiser JN, Paton JC, Andrew PW. Nat. Rev. Microbiol. 2008; 6:288-301. [PubMed: 18340341]

7. Liu JZ, Jellbauer S, Poe AJ, Ton V, Pesciaroli M, Kehl-Fie TE, Restrepo NA, Hosking MP, Edwards RA, Battistoni A, Pasquali P, Lane TE, Chazin WJ, Vogl T, Roth J, Skaar EP, Raffatellu M. Cell Host Microbe. 2012; 11:227-239. [PubMed: 22423963]

8. Corbin BD, Seeley EH, Raab A, Feldmann J, Miller MR, Torres VJ, Anderson KL, Dattilo BM, Dunman PM, Gerads R, Caprioli RM, Nacken W, Chazin WJ, Skaar EP. Science. 2008; 319:962965. [PubMed: 18276893]

9. Brophy MB, Hayden JA, Nolan EM. J. Am. Chem. Soc. 2012; 134:18089-18100. [PubMed: 23082970]

10. Hayden JA, Brophy MB, Cunden LS, Nolan EM. J. Am. Chem. Soc. 2013; 135:775-787. [PubMed: 23276281]

11. Brophy MB, Nakashige TG, Gaillard A, Nolan EM. J. Am. Chem. Soc. 2013; 135:17804-17817. [PubMed: 24245608]

12. Kehl-Fie TE, Chitayat S, Hood MI, Damo S, Restrepo N, Garcia C, Munro KA, Chazin WJ, Skaar EP. Cell Host Microbe. 2011; 10:158-164. [PubMed: 21843872]

13. Damo SM, Kehl-Fie TE, Sugitani N, Holt ME, Rathi S, Murphy WJ, Zhang Y, Betz C, Hench L, Fritz G, Skaar EP, Chazin WJ. Proc. Natl. Acad. Sci. U. S. A. 2013; 110:3841-3846. [PubMed: 23431180]

14. Donato R. Biochim. Biophys. Acta. 1999; 1450:191-231. [PubMed: 10395934]

15. Heizmann CW, Cox JA. Biometals. 1998; 11:383-397. [PubMed: 10191501]

16. Hunter MJ, Chazin WJ. J. Biol. Chem. 1998; 273:12427-12435. [PubMed: 9575199]

17. Leukert N, Vogl T, Strupat K, Reichelt R, Sorg C, Roth J. J. Mol. Biol. 2006; 359:961-972. [PubMed: 16690079]

18. Korndörfer IP, Brueckner F, Skerra A. J. Mol. Biol. 2007; 370:887-898. [PubMed: 17553524]

19. Vogl T, Roth J, Sorg C, Hillenkamp F, Strupat K. J. Am. Soc. Mass Spectrom. 1999; 10:11241130. [PubMed: 10536818]

20. Gifford JL, Walsh MP, Vogel HJ. Biochem. J. 2007; 405:199-221. [PubMed: 17590154]

21. Persechini A, Moncrief ND, Kretsinger RH. Trends Neurosci. 1989; 12:462-467. [PubMed: 2479149]

22. Santamaria-Kisiel L, Rintala-Dempsey AC, Shaw GS. Biochem. J. 2006; 396:201-214. [PubMed: 16683912]

23. Eckert RL, Broome A-M, Ruse M, Robinson N, Ryan D, Lee K. J. Invest. Dermatol. 2004; 123:23-33. [PubMed: 15191538]

24. Garrett SC, Hodgson L, Rybin A, Toutchkine A, Hahn KM, Lawrence DS, Bresnick AR. Biochemistry. 2008; 47:986-996. [PubMed: 18154362]

25. Donato R. Cell Calcium. 1986; 7:123-145. [PubMed: 3521884]

26. Morin A, Eisenbraun B, Key J, Sanschagrin PC, Timony MA, Ottaviano M, Sliz P. eLife. 2013; 2:e01456. [PubMed: 24040512]

27. Minor W, Cymborowski M, Otwinowski Z, Chruszcz M. Acta Crystallogr. D. 2006; 62:859-866. [PubMed: 16855301]

28. McCoy AJ, Grosse-Kunstleve RW, Adams PD, Winn MD, Storoni LC, Read RJ. J. Appl. Crystallogr. 2007; 40:658-674. [PubMed: 19461840]

29. Adams PD, Afonine PV, Bunkóczi G, Chen VB, Davis IW, Echols N, Headd JJ, Hung L-W, Kapral GJ, Grosse-Kunstleve RW, McCoy AJ, Moriarty NW, Oeffner R, Read RJ, Richardson DC, Richardson JS, Terwilliger TC, Zwart PH. Acta Crystallogr. D. 2010; 66:213-221. [PubMed: 20124702]

30. Emsley P, Lohkamp B, Scott WG, Cowtan K. Acta Crystallogr. D. 2010; 66:486-501. [PubMed: 20383002]

31. Sienkiewicz A, Smith BG, Veselov A, Scholes CP. Rev. Sci. Instrum. 1996; 67:2134-2138.

32. Mims WB. Proc. R. Soc. Lond. 1965; 283:452-457.

J Am Chem Soc. Author manuscript; available in PMC 2016 March 04. 
33. Gemperle C, Aebli G, Schweiger A, Ernst RR. J. Magn. Reson. 1990; 88:241-256.

34. Van Doorslaer S, Sierra GA, Schweiger A. J. Magn. Reson. 1999; 136:152-158. [PubMed: 9986757]

35. Stoll S, Schweiger A. J. Magn. Reson. 2006; 178:42-55. [PubMed: 16188474]

36. Hoogstraten CG, Britt RD. RNA. 2002; 8:252-260. [PubMed: 11911370]

37. Hoogstraten CG, Grant CV, Horton TE, DeRose VJ, Britt RD. J. Am. Chem. Soc. 2002; 124:834842. [PubMed: 11817959]

38. Mims, WB.; Peisach, J. Biological Magnetic Resonance. Vol. 3. Springer US; Boston, MA: 1981. p. 213-263.

39. Dikanov SA, Shubin AA, Parmon VN. J. Magn. Reson. 1981; 42:474-487.

40. Dong G-Y, Liu T-F, He C-H, Deng X-C, Shi X-G. Acta Crystallogr. Sect. E. 2011; 67:m960.

41. Niu S-Y, Zhang S-S, Li X-M, Wen Y-H, Jiao K. Acta Crystallogr. Sect. E. 2004; 60:m209.

42. Durot S, Policar C, Cisnetti F, Lambert F, Renault J-P, Pelosi G, Blain G, Korri-Youssoufi H, Mahy J-P. Eur. J. Inorg. Chem. 2005; 2005:3513-3523.

43. Lemoine P, Viossat V, Dayan E, Dung N-H, Viossat B. Inorg. Chim. Acta. 2006; 359:4274-4280.

44. Dev S, Ramli E, Rauchfuss TB, Wilson SR. Inorg. Chem. 1991; 30:2514-2519.

45. Garrett TPJ, Guss JM, Freeman HC. Acta Crystallogr. C. 1983; 39:1027-1031.

46. García-Rubio I, Angerhofer A, Schweiger A. J. Magn. Reson. 2007; 184:130-142. [PubMed: 17055309]

47. Angerhofer A, Moomaw EW, García-Rubio I, Ozarowski A, Krzystek J, Weber RT, Richards NGJ. J. Phys. Chem. B. 2007; 111:5043-5046. [PubMed: 17444678]

48. Meirovitch E, Luz Z, Kalb AJ. J. Am. Chem. Soc. 1974; 96:7542-7546. [PubMed: 4372266]

49. Reed GH, Markham GD. Biological Magnetic Resonance. 1984:73-142.

50. Walsby CJ, Telser J, Rigsby RE, Armstrong RN, Hoffman BM. J. Am. Chem. Soc. 2005; 127:8310-8319. [PubMed: 15941264]

51. Duboc C, Phoeung T, Zein S, Pécaut J, Collomb M-N, Neese F. Inorg. Chem. 2007; 46:49054916. [PubMed: 17508742]

52. Duboc C, Collomb M-N, Neese F. Appl. Magn. Reson. 2010; 37:229-245.

53. Un S. Inorg. Chem. 2013; 52:3803-3813. [PubMed: 23510244]

54. Campomanes P, Kellett WF, Easthon LM, Ozarowski A, Allen KN, Angerhofer A, Rothlisberger U, Richards NGJ. J. Am. Chem. Soc. 2014; 136:2313-2323. [PubMed: 24444454]

55. Espe MP, Hosler JP, Ferguson-Miller S, Babcock GT, McCracken J. Biochemistry. 1995; 34:7593-7602. [PubMed: 7779805]

56. Bleaney B, Rubins RS. Proc. Phys. Soc. 1961; 77:103-112.

57. Mims WB, Peisach J. J. Chem. Phys. 1978; 69:4921-4930.

58. Zweier J, Aisen P, Peisach J, Mims WB. J. Biol. Chem. 1979; 254:3512-3515. [PubMed: 218971]

59. Deligiannakis Y, Louloudi M, Hadjiliadis N. Coord. Chem. Rev. 2000; 204:1-112.

60. Matar K, Goldfarb D. J. Magn. Reson. Ser. A. 1994; 111:50-61.

61. Vogt M, Lahiri S, Hoogstraten CG, Britt RD, DeRose VJ. J. Am. Chem. Soc. 2006; 128:1676416770. [PubMed: 17177426]

62. Geue RJ, Hambley TW, Harrowfield JM, Sargeson AM, Snow MR. J. Am. Chem. Soc. 1984; 106:5478-5488.

63. Martin LL, Martin JRL, Murray IKS, Ja AM. S. Inorg. Chem. 1990; 29:1387-1394.

64. Horton TE, Clardy DR, DeRose VJ. Biochemistry. 1998; 37:18094-18101. [PubMed: 9922178]

65. Cohn M, Townsend J. Nature. 1954; 173:1090-1091.

66. Whittaker JW, Whittaker MM. J. Am. Chem. Soc. 1991; 113:5528-5540.

67. Smoukov SK, Telser J, Bernat BA, Rife CL, Armstrong RN, Hoffman BM. J. Am. Chem. Soc. 2002; 124:2318-2326. [PubMed: 11878987]

68. Berliner LJ, Ellis PD, Murakami K. Biochemistry. 1983; 22:5061-5063. [PubMed: 6317012]

69. Senguen FT, Grabarek Z. Biochemistry. 2012; 51:6182-6194. [PubMed: 22803592]

J Am Chem Soc. Author manuscript; available in PMC 2016 March 04. 
70. Moroz OV, Blagova EV, Wilkinson AJ, Wilson KS, Bronstein IB. J. Mol. Biol. 2009; 391:536551. [PubMed: 19501594]

71. Koch M, Diez J, Fritz G. J. Mol. Biol. 2008; 378:933-942. [PubMed: 18394645] 

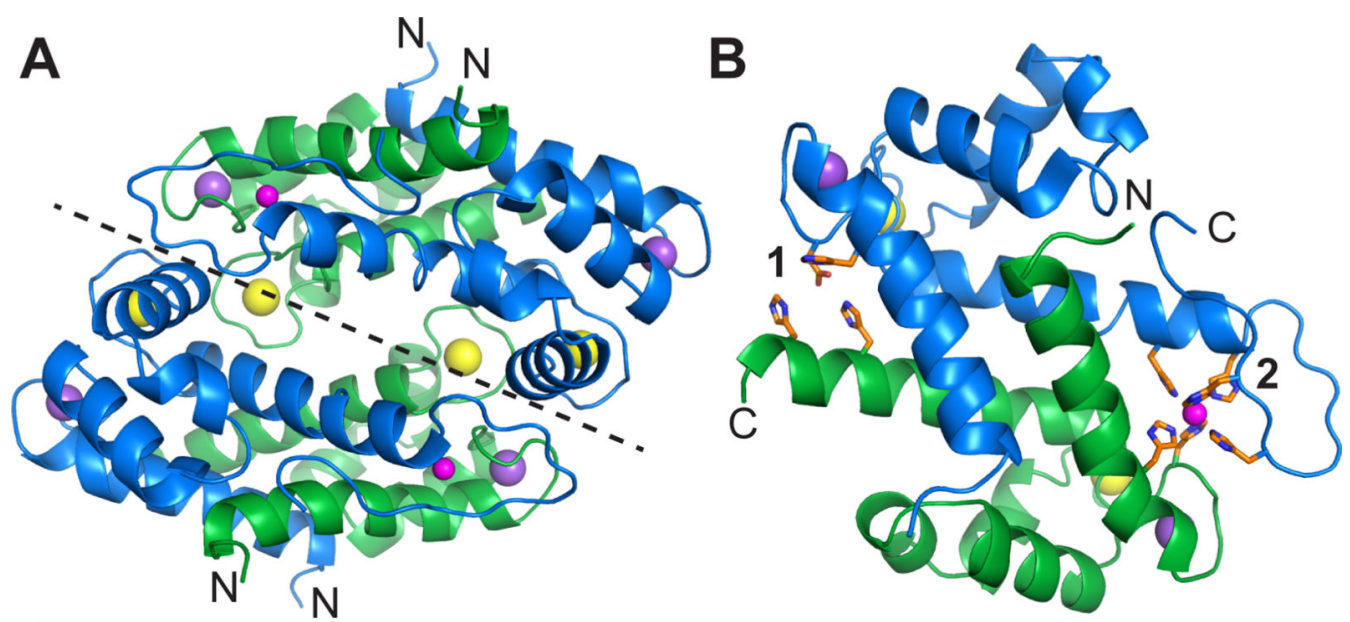

C

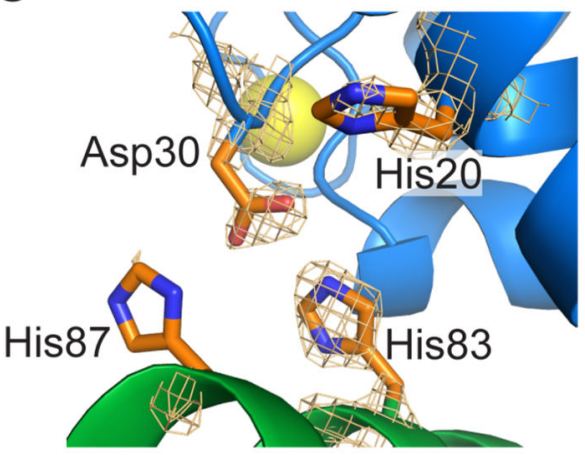

D

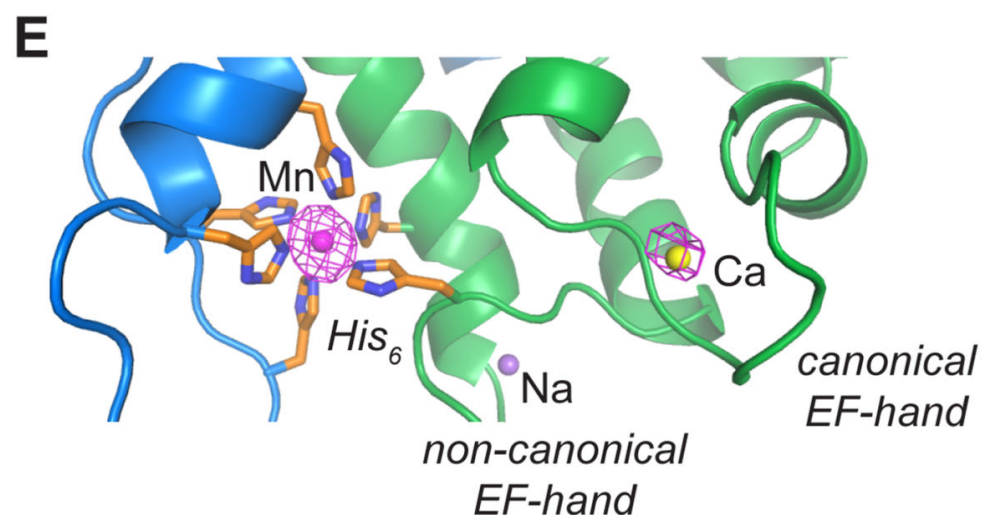

Figure 1.

Crystal structure of $\mathrm{Ca}(\mathrm{II})-, \mathrm{Na}(\mathrm{I})-$, and $\mathrm{Mn}$ (II)-bound CP-Ser (PDB ID 4XJK). (A) The $\mathrm{a}_{2} \beta_{2}$ tetramer of CP-Ser. The dashed line represents the dimer-dimer interface. (B) A representation of the $a \beta$ dimer of CP-Ser, taken from the tetramer structure shown in A. (C) Site 1 is a His 3 Asp motif comprised of (A8)His83, (A8)His87, (A9)His20 and (A9)Asp30. The composite omit electron density map at $3 \sigma$ is shown for transition-metal coordinating residues. (D) Site 2 is a His 6 motif comprised of residues (A8)His17, (A8)His27, (A9)His91,

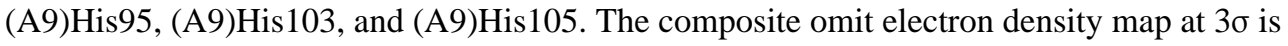
shown for the $\mathrm{Mn}$ (II)-coordinating residues and the $\mathrm{Mn}$ (II) ion. (E) The anomalous electron density, calculated from data collected at $\lambda=1.54 \AA$, for the $\mathrm{His}_{6}$ site, one canonical, and 
one non-canonical EF-hand of the S100A8 subunit are contoured at $4 \sigma$ with $\mathrm{Mn}(\mathrm{II}), \mathrm{Ca}(\mathrm{II})$, and $\mathrm{Na}(\mathrm{I})$ ions, respectively. Additional electron density maps are presented in Figure S4. S100A8 is shown in green, and S100A9 is shown in blue. Transition metal-ion coordinating residues are shown as orange sticks. $\mathrm{Ca}(\mathrm{II})$ ions are shown in yellow, $\mathrm{Na}(\mathrm{I})$ ions are shown in purple, and $\mathrm{Mn}(\mathrm{II})$ ions are shown in magenta. 


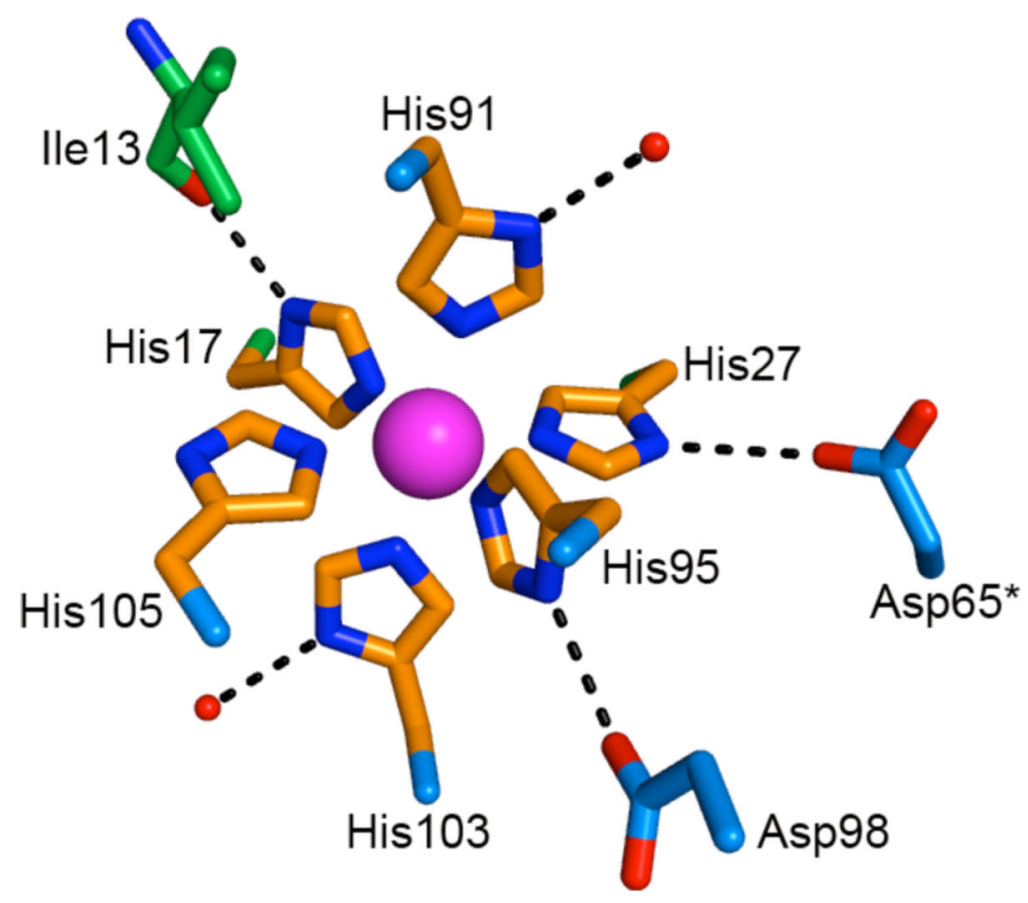

Figure 2.

Hydrogen-bonding interactions at the $\mathrm{Mn}(\mathrm{II})-\mathrm{His}_{6}$ site of $\mathrm{Mn}(\mathrm{II})-$ and $\mathrm{Ca}(\mathrm{II})$-bound $\mathrm{CP}-\mathrm{Ser}$. $\mathrm{Mn}$ (II)-coordinating residues are shown as orange sticks and the $\mathrm{Mn}$ (II) ion is represented as a pink sphere. Additional residues are shown as green (S100A8) or blue (S100A9) sticks. The asterisk indicates that the residue is derived from an adjacent "dimer" of the $\alpha_{2} \beta_{2}$ tetramer. 


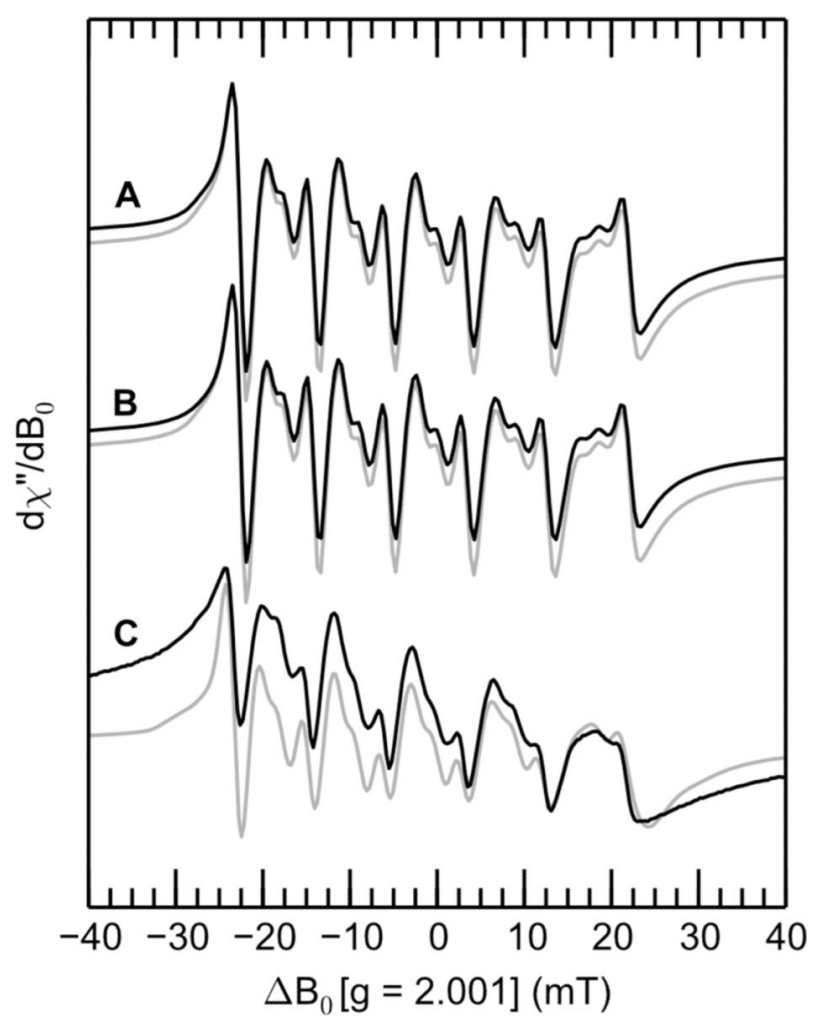

Figure 3.

X-band CW EPR spectra (black traces) and simulations (gray traces) of $\mathrm{Mn}$ (II)- and $\mathrm{Ca}(\mathrm{II})$ bound CP-Ser (A), $\Delta \mathrm{His}_{3} \mathrm{Asp}$ (B), and H103A (C). Simulation parameters are given in Table 2. Spectrometer settings: $v_{\mathrm{mw}}=9.4 \mathrm{GHz}, 0.5 \mathrm{mT}$ modulation at $100 \mathrm{KHz}$, power $=0.2 \mathrm{~mW}$, temperature $=10 \mathrm{~K}$. Sample conditions: $200 \mu \mathrm{M} \mathrm{CP}, 180 \mu \mathrm{M} \mathrm{Mn}(\mathrm{II}), 2.0 \mathrm{mM} \mathrm{Ca}(\mathrm{II})$ at $\mathrm{pH}$ 7.5 (75 mM HEPES, 100 mM NaCl, 20\% (v/v) PEG 200). 


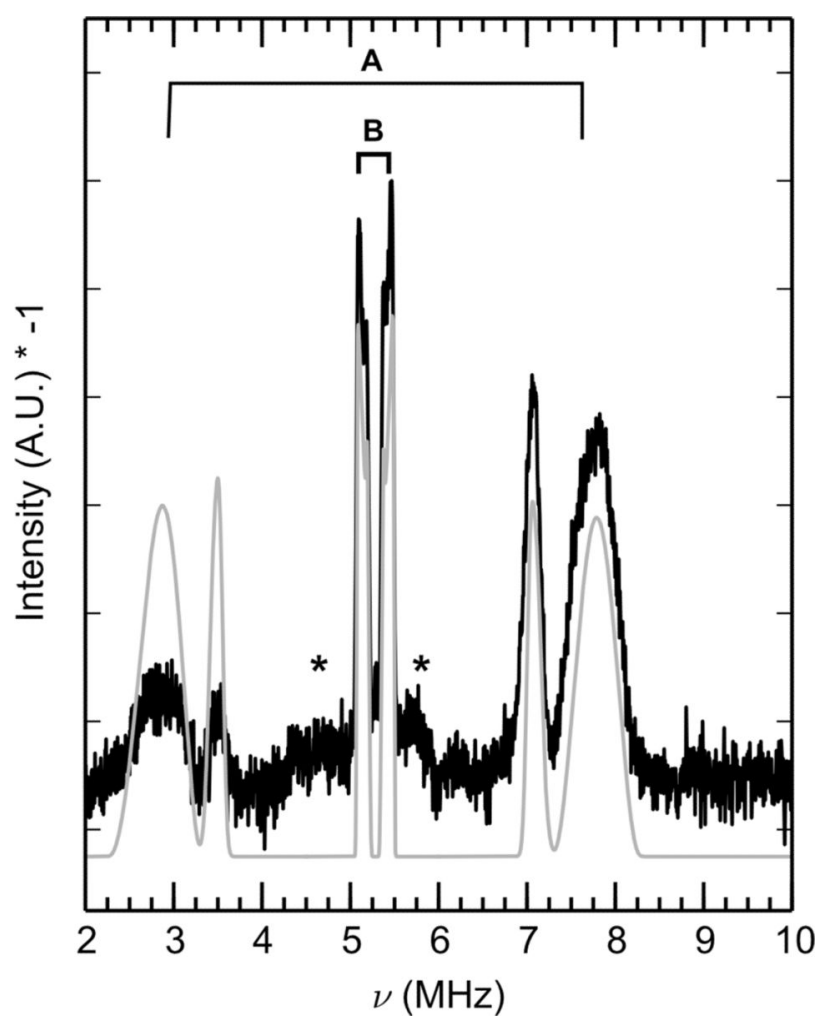

Figure 4.

Mims ENDOR spectrum (black) of $\mathrm{Mn}(\mathrm{II})$ - and $\mathrm{Ca}(\mathrm{II})$-bound ${ }^{15} \mathrm{~N}-\mathrm{CP}-\mathrm{Ser}$ collected at $\tau=$ $500 \mathrm{~ns}$ and simulation (gray). A corresponds to the proximal nitrogen of the imidazole ring. $\mathrm{B}$ corresponds to the distal nitrogen of the imidazole ring. The asterisk (*) indicates ${ }^{15} \mathrm{~N}$ ENDOR transitions coupled to the $m_{s}= \pm 1 / 2 \leftrightarrow m_{s}= \pm 3 / 2$ EPR transitions. Simulation of $m_{\mathrm{S}}$ $= \pm 1 / 2$ for the two classes of nitrogen atoms (gray) were obtained using the parameters listed in Table 3. Spectra at additional $\tau$ values are presented in Figure S6. Spectrometer settings: $v_{\mathrm{mw}}=34.1 \mathrm{GHz}, \mathrm{B}_{0}=1222.5 \mathrm{mT}, 8 \mathrm{~ns} \pi / 2$, temperature $=10 \mathrm{~K}$. Sample conditions: 200 $\mu \mathrm{M}{ }^{15} \mathrm{~N}-\mathrm{CP}-\mathrm{Ser}, 180 \mu \mathrm{M} \mathrm{Mn}(\mathrm{II}), 2.0 \mathrm{mM} \mathrm{Ca}(\mathrm{II})$ at pH 7.5 (75 mM HEPES, $100 \mathrm{mM} \mathrm{NaCl}$, $20 \%$ (v/v) PEG 200). 

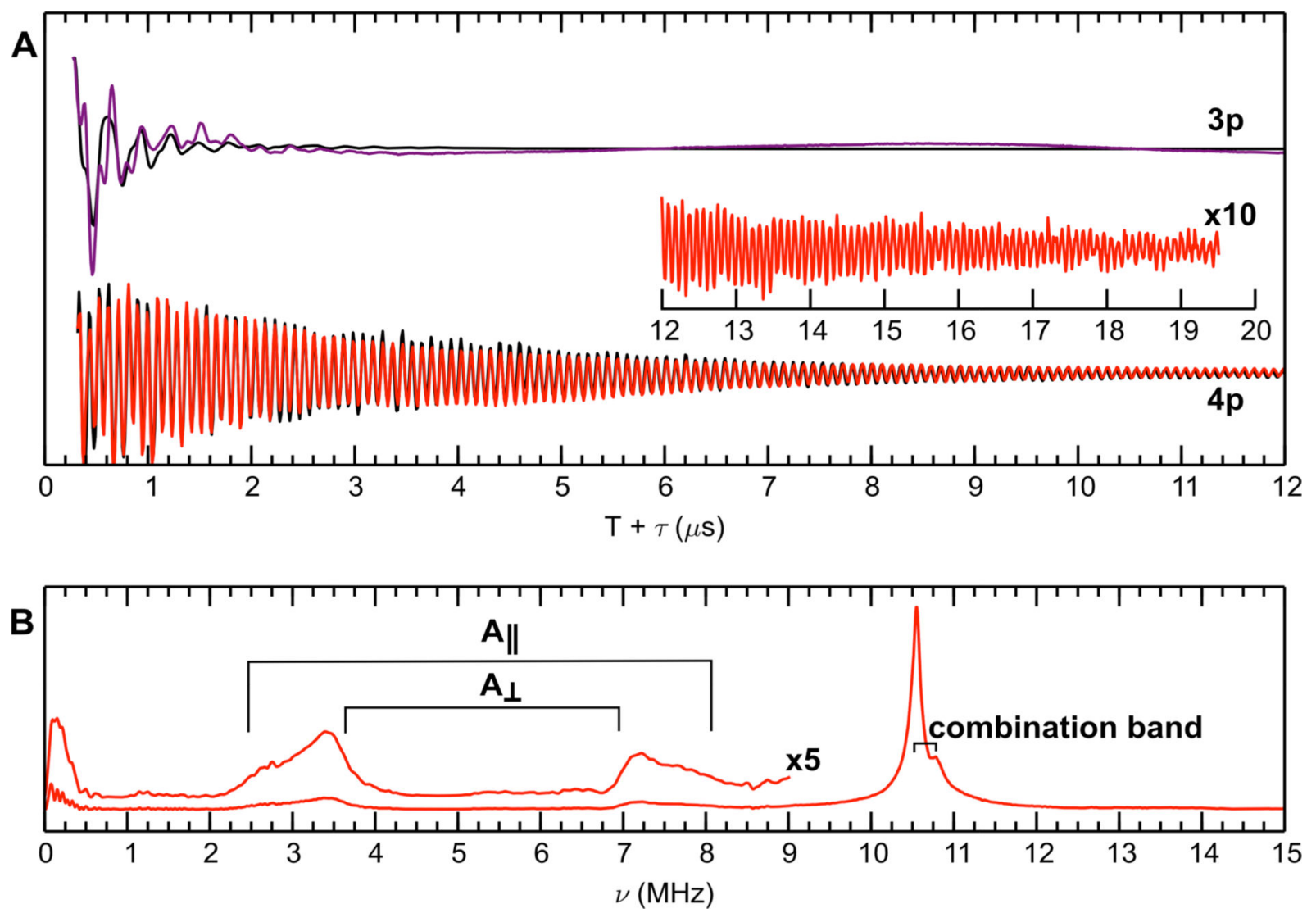

Figure 5.

3-pulse (purple line) and 4-pulse (red line) ESEEM of Mn(II)- and Ca(II)-bound ${ }^{15} \mathrm{~N}$-labeled CP-Ser at 34.1 GHz. The top panel (A) is the time domain. The bottom panel (B) is the Fourier transform of the 4-pulse ESEEM time domain. The black traces represent simulations of each spectrum, and the parameters are listed in Table 3. Spectrometer settings: $v_{\mathrm{mw}}=34.1 \mathrm{GHz}, \pi / 2=8 \mathrm{~ns}, \tau=200 \mathrm{~ns}, \mathrm{~T}_{0}=120 \mathrm{~ns}$, temperature $=10 \mathrm{~K}$, shot repetition time $=1500 \mu \mathrm{s}, \mathrm{B}_{0}=1223.7 \mathrm{mT}$. Sample conditions: $200 \mu \mathrm{M}^{15} \mathrm{~N}-\mathrm{CP}-\mathrm{Ser}, 180$ $\mu \mathrm{M}$ Mn(II), $2.0 \mathrm{mM} \mathrm{Ca}(\mathrm{II})$ at pH 7.5 (75 mM HEPES, $100 \mathrm{mM} \mathrm{NaCl,} 20 \%$ (v/v) PEG 200). 


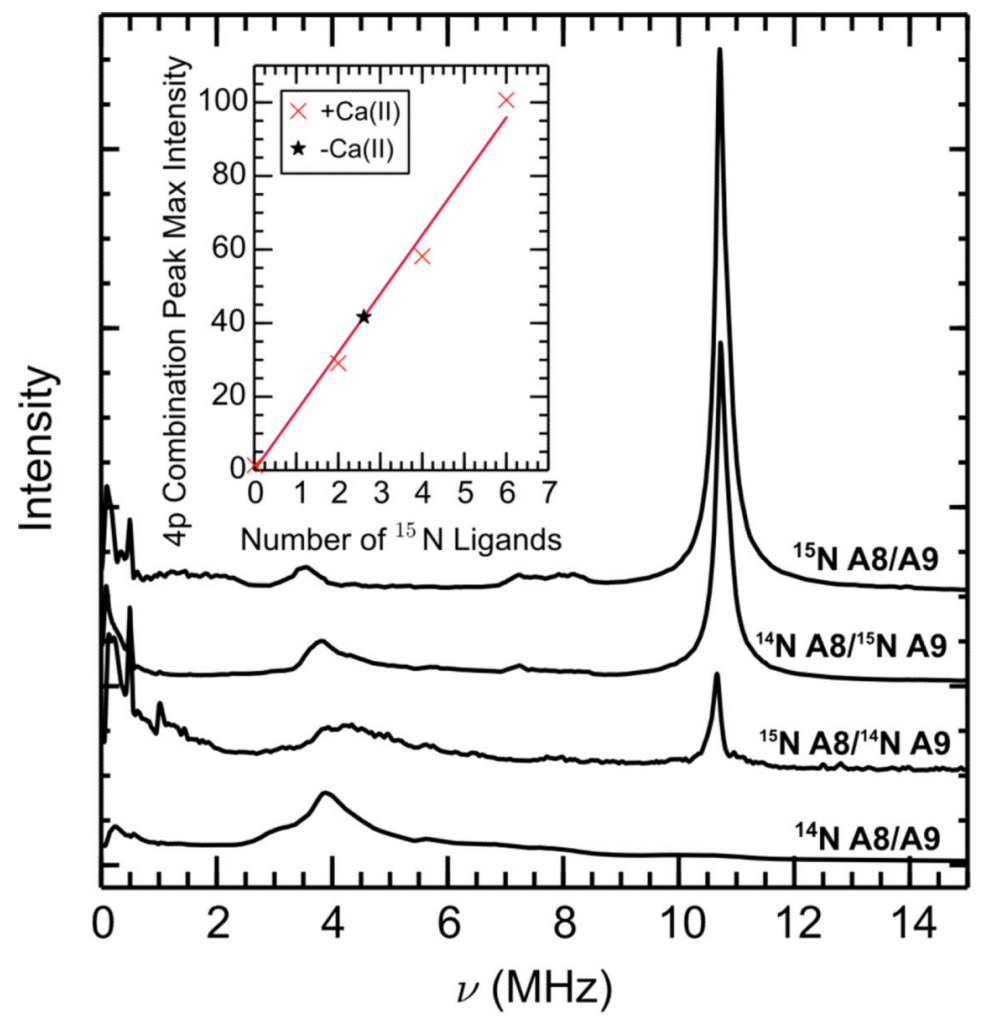

Figure 6.

Frequency domain of 4-pulse ESEEM spectra of $\mathrm{Mn}(\mathrm{II})$ - and $\mathrm{Ca}(\mathrm{II})$-bound mixed ${ }^{14} \mathrm{~N} /{ }^{15} \mathrm{~N}$ labeled $\Delta \mathrm{His}_{3} \mathrm{Asp}$ with 0.9 equivalents of $\mathrm{Mn}(\mathrm{II})$. The inset is a graph of maximum intensity of the combination peak vs the number of ${ }^{15} \mathrm{~N}$ ligands. The black $*$ represents the intensity of the ${ }^{15} \mathrm{~N}$ sum combination line measured for ${ }^{15} \mathrm{~N}$-labeled $\mathrm{Mn}$ (II)-CP in the absence of $\mathrm{Ca}(\mathrm{II})$ (vide infra) and was not used in the calculation of the best fit line. The number of ${ }^{15} \mathrm{~N}$ ligands for this point was calculated using the linear relationship determined from the bestfit line. Spectrometer settings: $v_{\mathrm{mw}}=34.1 \mathrm{GHz}, \mathrm{B}_{0}=1240 \mathrm{mT}, \pi / 2=8 \mathrm{~ns}, \tau=200 \mathrm{~ns}, \mathrm{~T}_{0}=$ $40 \mathrm{~ns}$, temperature $=10 \mathrm{~K}$. All samples contained $200 \mu \mathrm{M} \Delta \mathrm{His}_{3} \mathrm{Asp}, 2 \mathrm{mM} \mathrm{Ca}(\mathrm{II})$, and 180 $\mu \mathrm{M}$ Mn(II) at pH 7.5 (75 mM HEPES, $100 \mathrm{mM} \mathrm{NaCl,} \mathrm{20 \%} \mathrm{(v/v)} \mathrm{PEG} \mathrm{200).}$ 


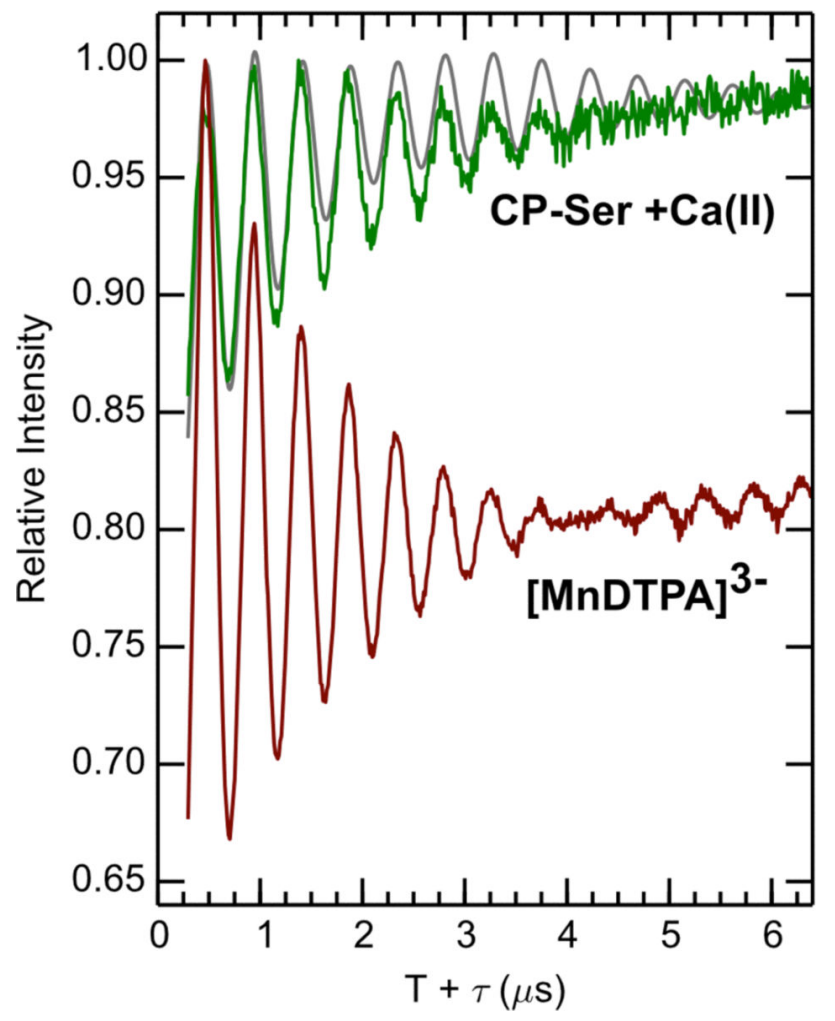

Figure 7.

${ }^{2} \mathrm{H}_{2} \mathrm{O} / \mathrm{H}_{2} \mathrm{O}$ 3-pulse ESEEM time domain of $\mathrm{Mn}$ (II)- and $\mathrm{Ca}$ (II)-bound CP-Ser (green) and [MnDTPA $]^{3-}$ (brown-red). Deuterons for the CP-Ser sample (gray line) are simulated with $\mathrm{r}_{\text {eff }}=3.6 \AA\left(a_{\text {iso }}=0 \mathrm{MHz}, T=0.26 \mathrm{MHz}\right)$. Spectrometer settings: $v_{\mathrm{mw}}=9.525(5) \mathrm{GHz}, \mathrm{B}_{0}$ $=327.35 \mathrm{mT}, \pi / 2=8 \mathrm{~ns}, \tau=216 \mathrm{~ns}, \mathrm{~T}_{0}=80 \mathrm{~ns}$, temperature $=10 \mathrm{~K}$. Sample conditions: $200 \mu \mathrm{M}$ CP, $180 \mu \mathrm{M} \mathrm{Mn}(\mathrm{II}), 2.0 \mathrm{mM}$ Ca(II) at pH 7.5 (75 mM HEPES, $100 \mathrm{mM} \mathrm{NaCl}, 20 \%$ (v/v) PEG 200). 


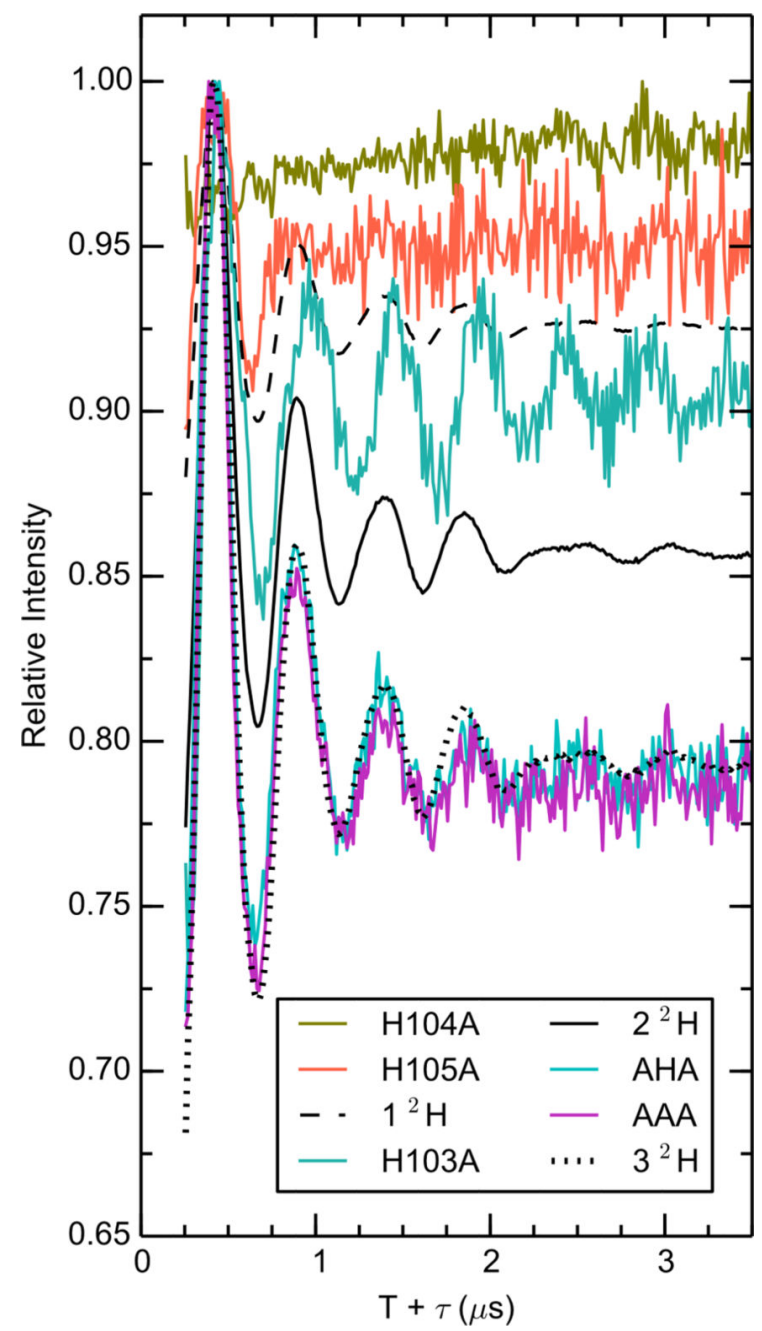

Figure 8.

Exchangeable proton counting of Mn(II) bound to H103A, H104A, H105A, AHA, or AAA. Black lines are calculated modulations for 1,2 , or 3 coordinating deuterons. Spectrometer settings: $v_{\mathrm{mw}}=9.525(5) \mathrm{GHz}, \mathrm{B}_{0}=327.35 \mathrm{mT}, 8 \mathrm{~ns} \pi / 2, \tau=216 \mathrm{~ns}, \mathrm{~T}_{0}=80 \mathrm{~ns}$, temperature $=10 \mathrm{~K}$. Sample conditions: $200 \mu \mathrm{M} \mathrm{CP}, 180 \mu \mathrm{M}$ Mn(II), $2.0 \mathrm{mM} \mathrm{Ca}(\mathrm{II}), \mathrm{pH} 7.5$ (75 mM HEPES, 100 mM NaCl, 20\% (v/v) PEG 200). 


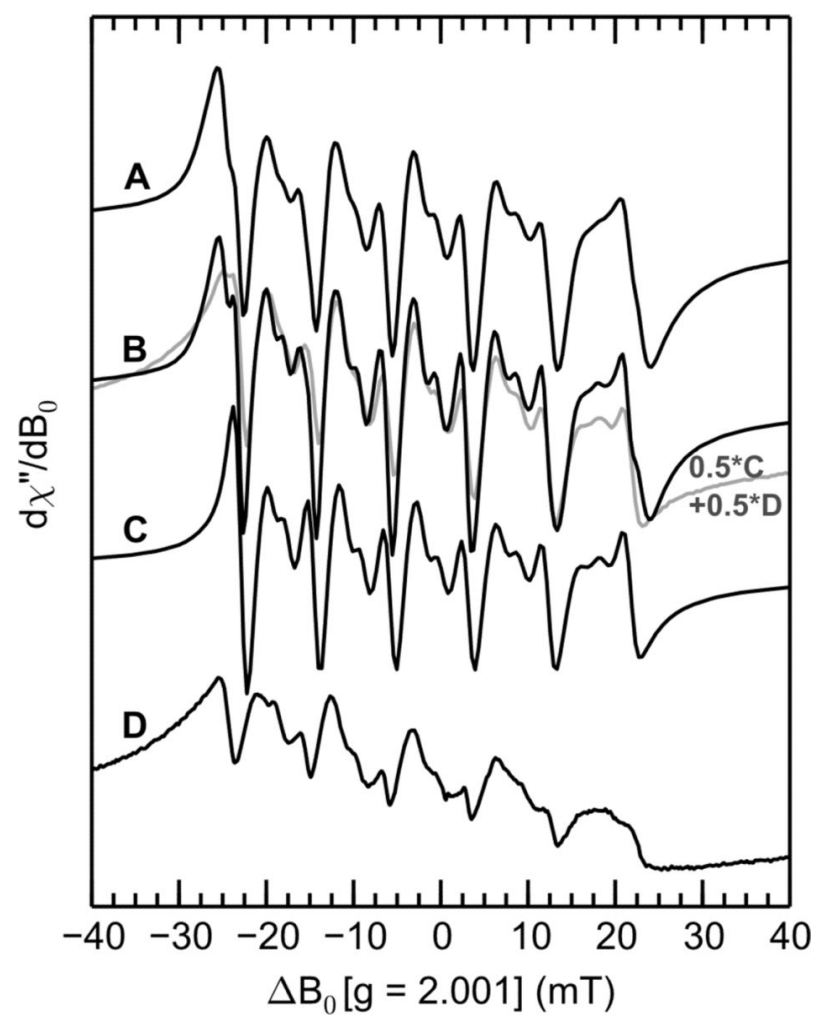

Figure 9.

X-band CW EPR spectra of (A) Mn(II)-bound CP-Ser in $\mathrm{H}_{2} \mathrm{O}$, (B) Mn(II)-bound CP-Ser in ${ }^{2} \mathrm{H}_{2} \mathrm{O}$, (C) $\mathrm{Mn}$ (II)- and $\mathrm{Ca}$ (II)-bound CP-Ser in ${ }^{2} \mathrm{H}_{2} \mathrm{O}$, (D) $200 \mu \mathrm{M} \mathrm{MnCl}_{2}$ in ${ }^{2} \mathrm{H}_{2} \mathrm{O}$ with $20 \%(\mathrm{v} / \mathrm{v})$ PEG 200. The gray trace is a linear combination of $1 / 2 \mathrm{C}$ and $1 / 2 \mathrm{D}$. Spectrometer settings: $v_{\mathrm{mw}}=9.4 \mathrm{GHz}, 0.5 \mathrm{mT}$ modulation at $100 \mathrm{KHz}$, power $=0.2 \mathrm{~mW}$, temperature $=$ $10 \mathrm{~K}$. Protein sample conditions: $1 \mathrm{mM}$ CP-Ser (-Ca) or $200 \mu \mathrm{M}$ CP-Ser (+Ca), $180 \mu \mathrm{M}$ Mn(II), pH 7.5 (75 mM HEPES, $100 \mathrm{mM} \mathrm{NaCl}, 20 \%$ (v/v) PEG 200), $\pm 2 \mathrm{mM} \mathrm{Ca(II).}$ 


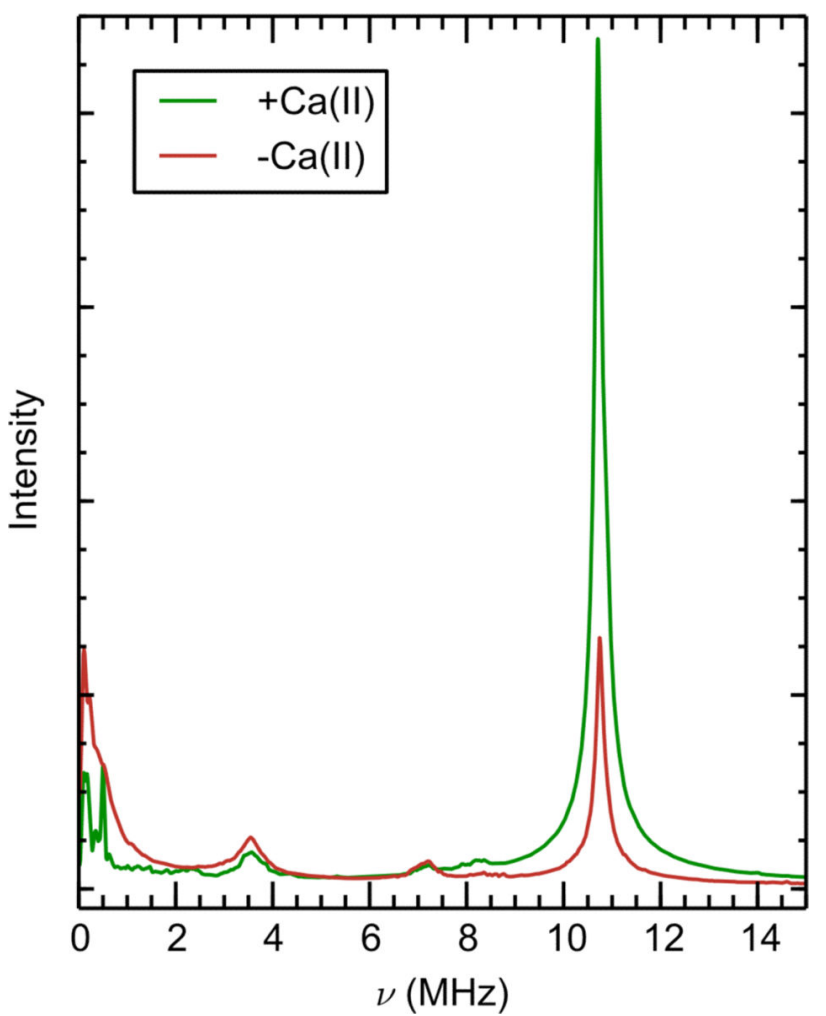

Figure 10.

4-pulse ESEEM frequency domain of 0.18:1 Mn(II): ${ }^{15} \mathrm{~N}-\mathrm{CP}-\mathrm{Ser}$ (red) and Mn(II)- and $\mathrm{Ca}$ (II)-bound to ${ }^{15} \mathrm{~N}-\mathrm{CP}$-Ser. The concentration of $\mathrm{Mn}(\mathrm{II})$ in both spectra is $180 \mu \mathrm{M}$.

Spectrometer settings: $v_{\mathrm{mw}}=34.1 \mathrm{GHz}, \mathrm{B}_{0} \sim 1240 \mathrm{mT}, \pi / 2=8 \mathrm{~ns}, \tau=200 \mathrm{~ns}, \mathrm{~T}_{0}=80 \mathrm{~ns}$, temperature $=10 \mathrm{~K}$. Protein sample conditions: $1 \mathrm{mM} \mathrm{CP}-\mathrm{Ser}(-\mathrm{Ca})$ or $200 \mu \mathrm{M} \mathrm{CP}-\mathrm{Ser}$ (+Ca), $180 \mu \mathrm{M}$ Mn(II), pH 7.5 (75 mM HEPES, $100 \mathrm{mM} \mathrm{NaCl,} \mathrm{20 \%} \mathrm{(v/v)} \mathrm{PEG} \mathrm{200,} \pm 2$ mM Ca(II). 


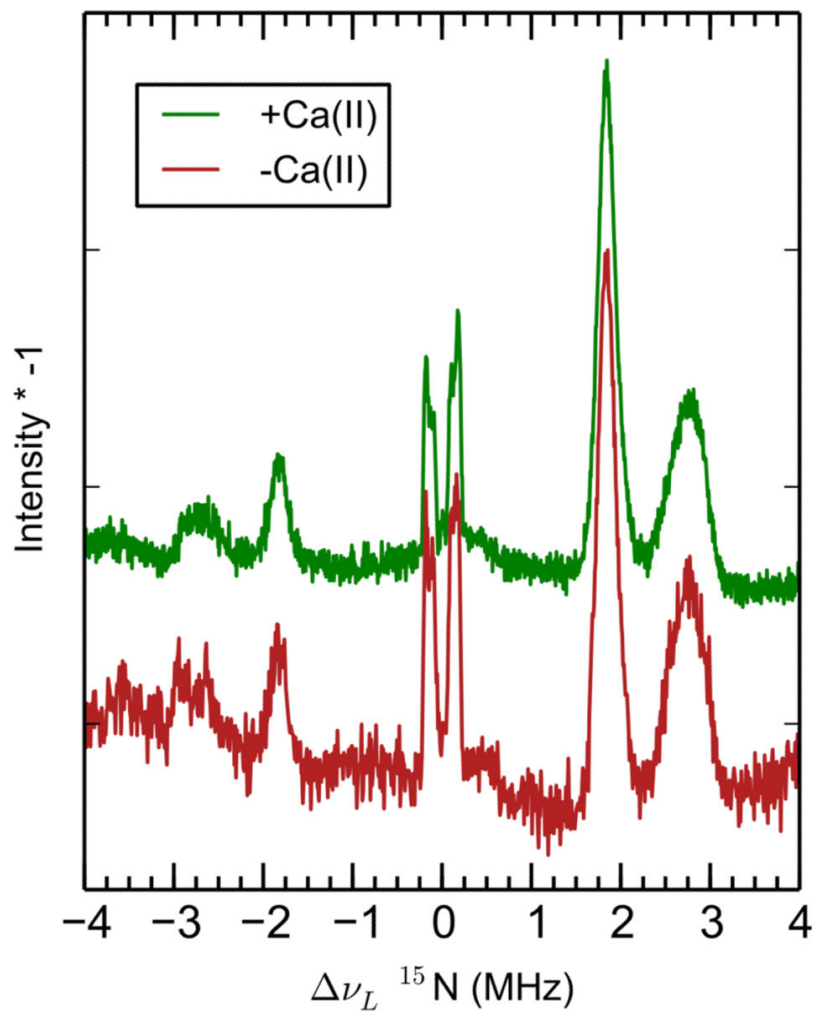

Figure 11.

Mims-ENDOR of Mn(II)-bound ${ }^{15} \mathrm{~N}-\mathrm{CP}-\mathrm{Ser}$ in the absence (red) and presence (green) of $\mathrm{Ca}(\mathrm{II})$. Spectrometer settings: $v_{\mathrm{mw}}=34 \mathrm{GHz}, \mathrm{B}_{0} \sim 1240 \mathrm{mT}, \pi / 2=8 \mathrm{~ns}, \tau=448 \mathrm{~ns}, \mathrm{~T}=400$ $\mathrm{ns}$, temperature $=10 \mathrm{~K}$. Protein sample conditions: $1 \mathrm{mM} \mathrm{CP-Ser}(-\mathrm{Ca})$ or $200 \mu \mathrm{M} \mathrm{CP}-\mathrm{Ser}$ (+Ca), $180 \mu \mathrm{M}$ Mn(II), pH 7.5 (75 mM HEPES, 100 mM NaCl, 20\% (v/v) PEG 200), \pm 2 $\mathrm{mM} \mathrm{Ca}(\mathrm{II})$. 


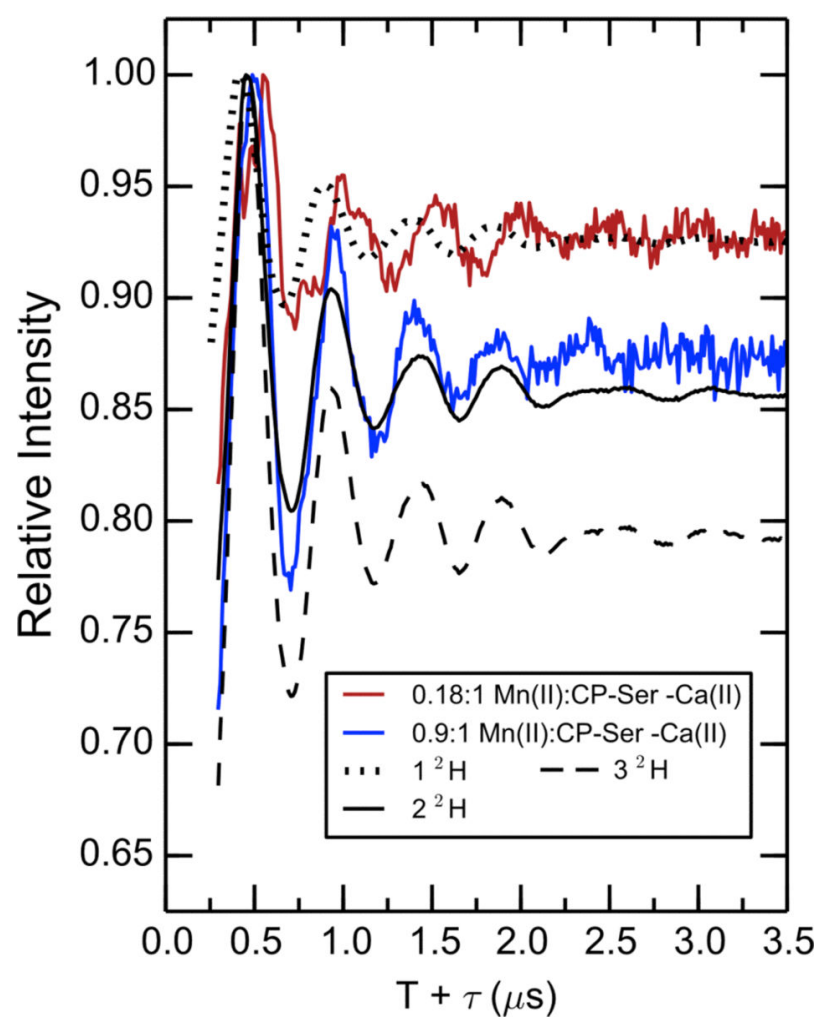

Figure 12.

Exchangeable proton counting of $\mathrm{Mn}(\mathrm{II})$-bound $\mathrm{CP}-$ Ser with varying ratios of $\mathrm{Mn} / \mathrm{CP}$. Spectrometer settings: $v_{\mathrm{mw}}=9.525(5) \mathrm{GHz}, \mathrm{B}_{0}=327.35 \mathrm{mT}, \pi / 2=8 \mathrm{~ns}, \tau=216 \mathrm{~ns}, \mathrm{~T}_{0}=$ $80 \mathrm{~ns}$, temperature $=10 \mathrm{~K}$. Protein sample conditions: $1 \mathrm{mM} \mathrm{CP-Ser}$ (red) or $200 \mu \mathrm{M} \mathrm{CP}-$ Ser (blue), $180 \mu \mathrm{M}$ Mn(II), pH 7.5 (75 mM HEPES, 100 mM NaCl, 20\% (v/v) PEG 200). 


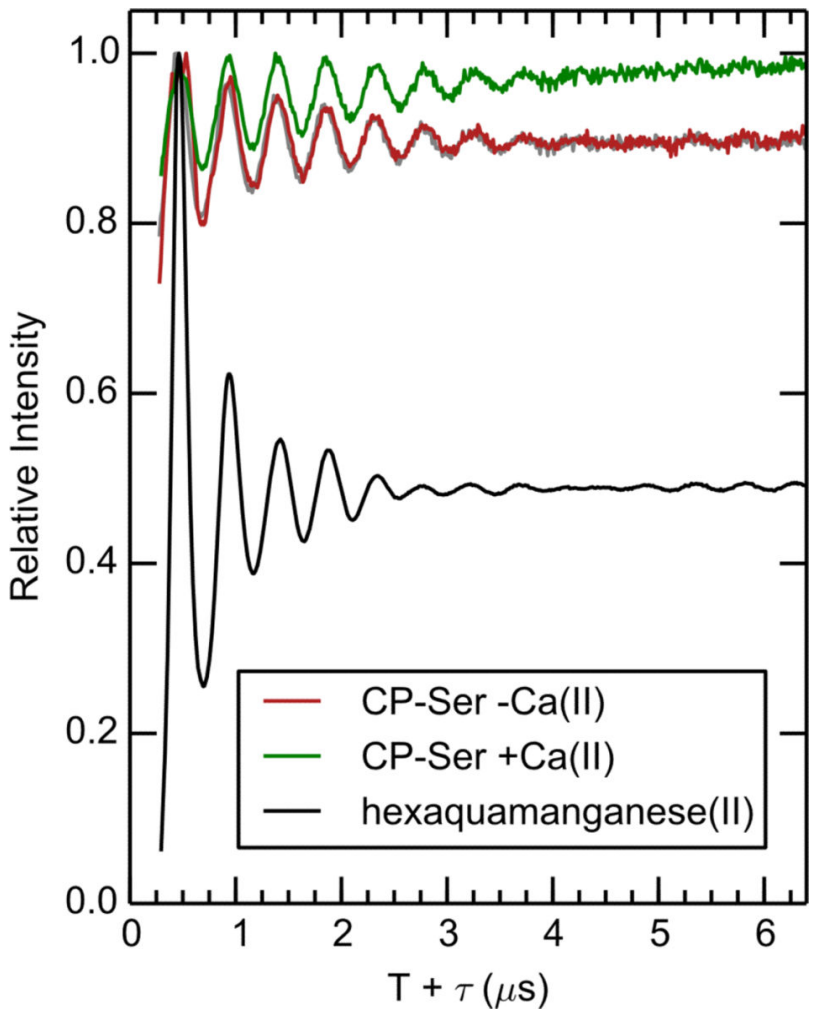

Figure 13.

${ }^{2} \mathrm{H}_{2} \mathrm{O} / \mathrm{H}_{2} \mathrm{O} 3$-pulse ESEEM time domain of Mn(II)-bound CP-Ser in the absence (red) and presence (green) of $\mathrm{Ca}(\mathrm{II})$. The protein samples contain $180 \mu \mathrm{M}$ of $\mathrm{Mn}(\mathrm{II})$, and an equivalent concentration of manganese hexaaqua is shown in black. The gray line overlaying the $-\mathrm{Ca}$ (II) CP-Ser data is a linear combination of $0.12 *$ hexaquamanganese and 0.88* $\mathrm{Mn}(\mathrm{II})$ and $\mathrm{Ca}(\mathrm{II})$-bound CP-Ser. Spectrometer settings: $v_{\mathrm{mw}}=9.525(5) \mathrm{GHz}, \mathrm{B}_{0}=$ $327.35 \mathrm{mT}, \pi / 2=8 \mathrm{~ns}, \tau=216 \mathrm{~ns}, \mathrm{~T}_{0}=80 \mathrm{~ns}$, temperature $=10 \mathrm{~K}$. Sample conditions: 1.0 mM CP-Ser (-Ca) or $200 \mu \mathrm{M}$ CP-Ser (+Ca), $180 \mu \mathrm{M}$ Mn(II), pH 7.5 (75 mM HEPES, 100 $\mathrm{mM} \mathrm{NaCl}, 20 \%$ (v/v) PEG 200), $\pm 2 \mathrm{mM} \mathrm{Ca(II)}$. 
Table 1

Previously reported Ca(II)-coordination by S100A8 and S100A9 in $\mathrm{CP}^{a}$

\begin{tabular}{|c|c|c|c|}
\hline EF-hand & $\mathrm{Ca}(\mathrm{II})$-coordinating groups & Coordination number & Net charge \\
\hline A8, N-terminal Non-canonical & $\operatorname{Ser} 20(\mathrm{C}=\mathrm{O})^{b}, \operatorname{Lys} 23(\mathrm{C}=\mathrm{O}), \operatorname{Asn} 25(\mathrm{C}=\mathrm{O}), \operatorname{Ala} 28(\mathrm{C}=\mathrm{O}), \mathrm{H}_{2} \mathrm{O}$ & 5 & 0 \\
\hline A8, C-terminal Canonical & $\begin{array}{l}\text { Asp59 (O8), Asn61 (O } 8) \text {, Asp63 (O } 81) \text {, Ala65 (C=O) Glu70 (Oع1 } \\
\text { and } \mathrm{O} \varepsilon 2), \mathrm{H}_{2} \mathrm{O}\end{array}$ & 7 & -4 \\
\hline A9, N-terminal Non-canonical & $\begin{array}{l}\text { Ser23 }(\mathrm{C}=\mathrm{O}), \text { Leu26 }(\mathrm{C}=\mathrm{O}), \operatorname{His} 28(\mathrm{C}=\mathrm{O}), \text { Thr31 }(\mathrm{C}=\mathrm{O}) \text {, Glu36 } \\
(\mathrm{O} \varepsilon 1), \mathrm{H}_{2} \mathrm{O}\end{array}$ & 6 & -1 \\
\hline A9, C-terminal Canonical & $\begin{array}{l}\text { Asp67 }(\mathrm{O} \delta), \mathrm{Asn} 69(\mathrm{O} \delta), \mathrm{Asp} 71(\mathrm{O} \delta 1), \mathrm{Gln} 73(\mathrm{C}=\mathrm{O}), \mathrm{Glu} 78(\mathrm{O} \varepsilon 1 \\
\text { and } \mathrm{O} \varepsilon 2), \mathrm{H}_{2} \mathrm{O}\end{array}$ & 7 & -4 \\
\hline
\end{tabular}

${ }^{a}$ Taken from the crystal structure of the Ca(II)-bound CP-Ser heterotetramer (PDB 1XK4, reference ${ }^{18}$ ).

${ }^{b} \mathrm{C}=\mathrm{O}$ indicates coordination by the carbonyl oxygen of the peptide backbone. In the $1 \mathrm{XK} 4$ structure, the $\mathrm{Ca}(\mathrm{II})$ ions are modeled at $100 \%$ occupancy in the canonical C-terminal EF-hand sites, and the $\mathrm{Ca}(\mathrm{II})$ ions in the non-canonical N-terminal EF-hand sites are modeled at $70 \%$ occupancy. 
Table 2

Zero-field splitting parameters of select six-coordinate $\mathrm{Mn}$ (II) complexes

\begin{tabular}{|c|c|c|c|c|c|}
\hline Complex/Protein & $|\mathbf{D}|(\mathbf{M H z})$ & $|\mathbf{E}|(\mathbf{M H z})$ & $E / D$ & Coordination Motif & Reference \\
\hline $\operatorname{Mn}(\operatorname{Im})_{6}{ }^{a}$ & 354 & 66 & 0.19 & $\mathrm{~N}_{6}$ & 46 \\
\hline CP-Ser & 270 & 81 & 0.30 & $\mathrm{~N}_{6}$ & 10 \\
\hline CP-Ser & 485 & 145.5 & 0.30 & $\mathrm{~N}_{6}$ & This work \\
\hline$\Delta \mathrm{His}_{3} \mathrm{Asp}$ & 485 & 145.5 & 0.30 & $\mathrm{~N}_{6}$ & This work \\
\hline H103A & 650 & 105 & 0.30 & $\mathrm{~N}_{5} \mathrm{O}_{1}$ & This work \\
\hline OxDc (site 1) ${ }^{b}$ & 1200 & 250 & 0.21 & $\mathrm{~N}_{3} \mathrm{O}_{3}$ & 47 \\
\hline OxDc (site 2) & 2700 & 675 & 0.25 & $\mathrm{~N}_{3} \mathrm{O}_{3}$ & 47 \\
\hline Concanavalin A & 645 & 71 & 0.11 & $\mathrm{~N}_{1} \mathrm{O}_{5}$ & 48 \\
\hline Creatine kinase $\left(\mathrm{PO}_{4}{ }^{3-}\right) c$ & 673 & 108 & 0.16 & $\mathrm{O}_{6}$ & 49 \\
\hline Creatine kinase $\left(\mathrm{NO}_{3}{ }^{-}\right){ }^{c}$ & 1471 & 191 & 0.13 & $\mathrm{O}_{6}$ & 49 \\
\hline Creatine kinase $\left(\mathrm{NO}_{2}^{-}\right)^{c}$ & 1121 & 370 & 0.33 & $\mathrm{O}_{6}$ & 49 \\
\hline Fos A + fosfomycin $d$ & 6900 & 600 & 0.09 & $\mathrm{~N}_{2} \mathrm{O}_{3}$ & 50 \\
\hline $\begin{array}{l}\text { Mn(II) hexaimidazole. } \\
\text { Oxalate decarboxylase. }\end{array}$ & & & & & \\
\hline
\end{tabular}




\section{Table 3}

Hyperfine coupling (MHz) to magnetic nuclei in CP-Ser ${ }^{a}$

\begin{tabular}{lcccc}
\hline Nucleus & $\boldsymbol{a}_{\text {iso }}$ & $\boldsymbol{a}_{\mathbf{1}}$ & $\boldsymbol{a}_{\mathbf{2}}$ & $\boldsymbol{a}_{\mathbf{3}}$ \\
\hline${ }^{55} \mathrm{Mn}$ (II) & 247 & n.a. ${ }^{b}$ & n.a. & n.a. \\
${ }^{15} \mathrm{~N} \varepsilon 2$ (proximal) & 4.36 & 3.45 & 3.71 & 5.91 \\
${ }^{15} \mathrm{~N} \delta 1$ (distal) & 0.24 & 0.11 & 0.18 & 0.42 \\
${ }^{14} \mathrm{~N} \varepsilon 2$ (proximal) & 3.11 & 2.46 & 2.64 & 4.21 \\
${ }^{14} \mathrm{~N} \delta 1$ (distal) & 0.17 & 0.08 & 0.13 & 0.30 \\
$\mathrm{Mn}\left(\operatorname{Im}_{6}\right)$ (proximal $\left.{ }^{14} \mathrm{~N}\right)$ & 3.19 & 2.50 & 2.62 & 4.45 \\
\hline
\end{tabular}

${ }^{a}$ Samples contained $200 \mu \mathrm{M}$ CP-Ser at pH 7.5 (75 mM HEPES, $100 \mathrm{mM} \mathrm{NaCl}$ ) with 10 equivalents of $\mathrm{Ca}$ (II) and 0.9 equivalents of $\mathrm{Mn}$ (II).

$b_{\text {n.a., not applicable. }}$

${ }^{c} \mathrm{Mn}(\operatorname{Im}) 6$ hyperfine coupling constants are taken from reference 46 . 